\title{
Water masses as a unifying framework for understanding the Southern Ocean Carbon Cycle
}

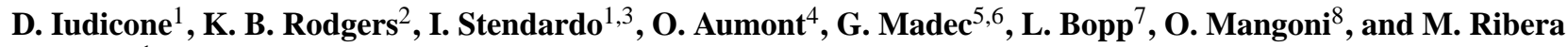 \\ d'Alcala' 1 \\ ${ }^{1}$ Stazione Zoologica Anton Dohrn, Naples, Italy \\ ${ }^{2}$ Atmospheric and Oceanic Sciences Program, Princeton University, Princeton, NJ, USA \\ ${ }^{3}$ Environmental Physics, Institute of Biogeochemistry and Pollutant Dynamics, ETH Zurich, Zurich, Switzerland \\ ${ }^{4}$ Laboratoire de Physique des Océans, (CNRS/IFREMER/IRD/UBO), Plouzané, France \\ ${ }^{5}$ Laboratoire d'Océanographie et du Climat: Expérimentations et Approches Numériques (LOCEAN/IPSL, \\ CNRS/IRD/UPMC/MNHN), Paris, France \\ ${ }^{6}$ National Oceanographic Centre, Southampton, UK \\ ${ }^{7}$ LSCE/IPSL (CNRS/CEA/UVSQ), Gif-sur-Yvette, France \\ ${ }^{8}$ Dipartimento delle Scienze Biologiche, Universitá di Napoli Federico II, Naples, Italy
}

Received: 14 April 2010 - Published in Biogeosciences Discuss.: 10 May 2010

Revised: 14 March 2011 - Accepted: 15 March 2011 - Published: 4 May 2011

\begin{abstract}
The scientific motivation for this study is to understand the processes in the ocean interior controlling carbon transfer across $30^{\circ} \mathrm{S}$. To address this, we have developed a unified framework for understanding the interplay between physical drivers such as buoyancy fluxes and ocean mixing, and carbon-specific processes such as biology, gas exchange and carbon mixing. Given the importance of density in determining the ocean interior structure and circulation, the framework is one that is organized by density and water masses, and it makes combined use of Eulerian and Lagrangian diagnostics. This is achieved through application to a global ice-ocean circulation model and an ocean biogeochemistry model, with both components being part of the widely-used IPSL coupled ocean/atmosphere/carbon cycle model.

Our main new result is the dominance of the overturning circulation (identified by water masses) in setting the vertical distribution of carbon transport from the Southern Ocean towards the global ocean. A net contrast emerges between the role of Subantarctic Mode Water (SAMW), associated with large northward transport and ingassing, and Antarctic Intermediate Water (AAIW), associated with a much smaller export and outgassing. The differences in their export rate reflects differences in their water mass formation processes. For SAMW, two-thirds of the surface waters are provided as
\end{abstract}

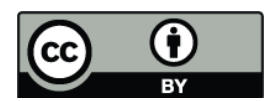

Correspondence to: D. Iudicone (iudicone@szn.it) a result of the densification of thermocline water (TW), and upon densification this water carries with it a substantial diapycnal flux of dissolved inorganic carbon (DIC). For AAIW, principal formatin processes include buoyancy forcing and mixing, with these serving to lighten CDW. An additional important formation pathway of AAIW is through the effect of interior processing (mixing, including cabelling) that serve to densify SAMW.

A quantitative evaluation of the contribution of mixing, biology and gas exchange to the DIC evolution per water mass reveals that mixing and, secondarily, gas exchange, effectively nearly balance biology on annual scales (while the latter process can be dominant at seasonal scale). The distribution of DIC in the northward flowing water at $30^{\circ} \mathrm{S}$ is thus primarily set by the DIC values of the water masses that are involved in the formation processes.

\section{Introduction}

What is the role of the Southern Ocean carbon cycle in the global climate system? It has long been suggested that the Southern Ocean could play a critical role on global climate variations given that it serves as a window between the atmospheric reservoir and the ocean interior. More recent work has pointed out that variations in stratification and ocean circulation in areas connected to the frontal systems associated with the Antarctic Circumpolar Current can impact

Published by Copernicus Publications on behalf of the European Geosciences Union. 


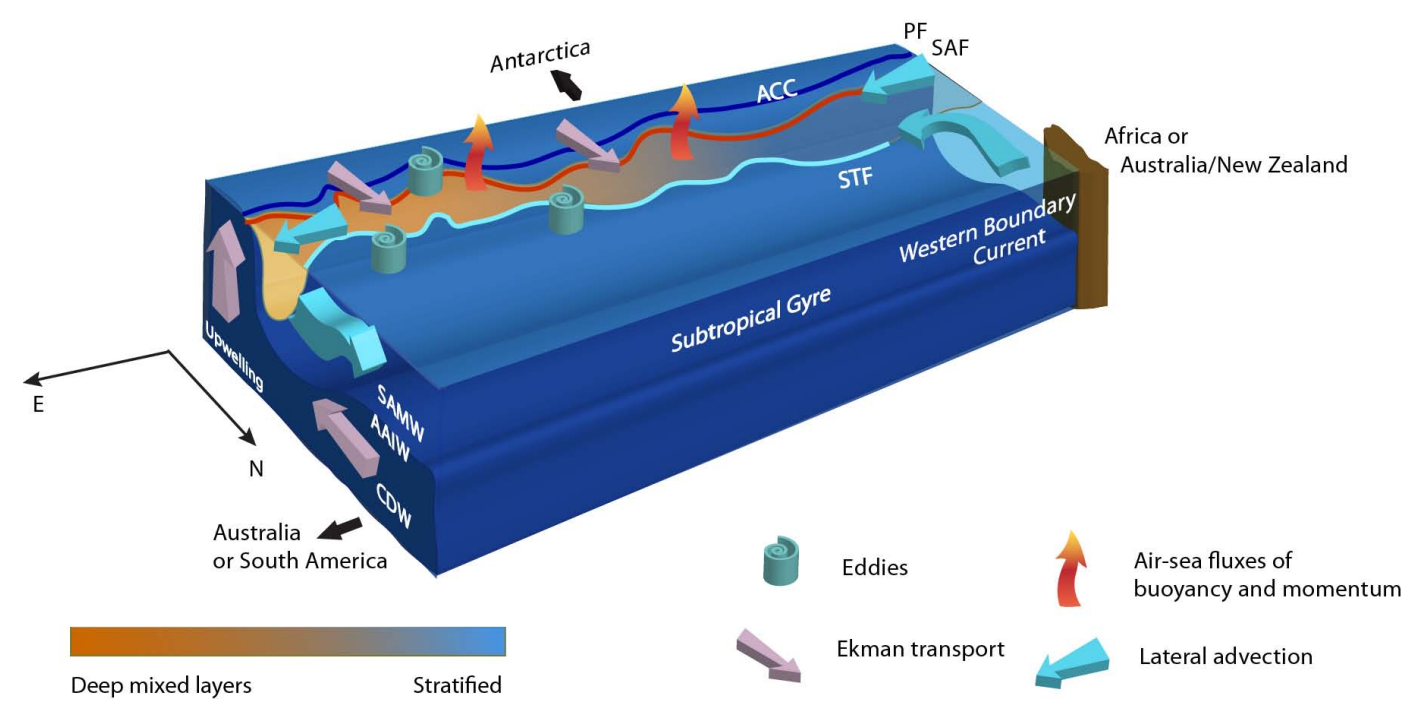

Fig. 1. Schematic diagram of processes involved in the formation of SAMW in the Indian and Pacific sectors of the Southern Ocean. The formation occurs in the winter deep mixed layers observed north of the subantarctic front (SAF; a component of the Antarctic Circumpolar Current, ACC) and south of the subtropical front (STF), in the eastern regions of the sectors (e.g., McCartney, 1977; Talley et al., 2003; Sallée et al., 2006). The formation is the result of the combined effect of Ekman transport, mesoscale (eddy) and sub-mesoscale lateral mixing and air-sea exchange of momentum and buoyancy, all acting on the incoming sub-tropical waters. The relative impact of each process on water mass formation is likely to be different for each of the formation sites.

the carbon cycle at global scale. This has been suggested for timescales ranging from decadal (Le Quéré et al., 2007) to millennial (Anderson et al., 2009). These studies drew on a wide range of inferences from model simulations to observations to paleo-proxy records and emphasize the importance of carbon/climate coupling involving the Southern Ocean. This underscores the need for a deep understanding of the ocean mechanisms controlling the exchange of carbon between the oceanic and atmospheric reservoirs. In fact, while sensitivity studies are adding insight on the issue (e.g., d'Orgeville et al., 2010), a quantitative understanding of the interplay between ocean circulation and carbon dynamics is still missing.

Research over the last several decades has firmly established that the Southern Ocean serves as a water mass crossroads for the global ocean circulation (e.g., Sloyan and Rintoul, 2001; Lumpkin and Speer, 2007 and references therein) as well as for global biogeochemical cycles (Sarmiento et al., 2004; Marinov et al., 2006, and references therein). Given that much of the water that enters the Southern Ocean (southward flow across $30^{\circ} \mathrm{S}$ ) does so at a different density than its outflow from the Southern Ocean, this implicates water mass transformations as being an intrinsic part of the large-scale circulation and thereby carbon cycle of the Southern Ocean.

Here we present a new framework for understanding the Southern Ocean carbon cycle. This is known to be impacted by a wide variety of processes, including biology, mixing, advective transport, water mass transformations near the surface. We develop this within the context of the mean cyclostationary pre-industrial state for a global model, where sea- sonal variations are accounted for. Although our long-term interests are in climate perturbations and climate change, it is clear that it is first necessary to develop a framework that can bring together the processes that are known to play important roles in controlling the Southern Ocean carbon cycle and its connection with the global cycle.

We have chosen to develop a framework for quantifying and understanding the relative contributions of these processes that is anchored in ocean Water masses. water masses are the phenomenological expression of large-scale ocean dynamical processes, and since the beginning of oceanography have for this reason been the foundation of our characterization and understanding of large-scale circulation structures in the ocean. The (implicit) concept of water masses is in fact already ubiquitous in empirical studies in ocean biogeochemistry that consider pre-formed nutrients and carbon (pre-formed refers to the tracer value at the moment of the water mass formation). They are at the basis of the isopycnal characterization of pre-formed carbon that was used to estimate anthropogenic carbon inventories in the ocean during the WOCE era (Sabine et al., 2004). The usefulness of this approach stems directly from large-scale dynamical controls on ocean biogeochemistry via ventilation and interior circulation.

Over the upper $1 \mathrm{~km}$ the large-scale exchange of waters between the Southern Ocean and the lower latitudes of the Southern Hemisphere occurs through the exchange of SubAntarctic Mode Water (SAMW) and Antarctic Intermediate Water (AAIW) (see Fig. 1 for a schematic of SAMW formation). 


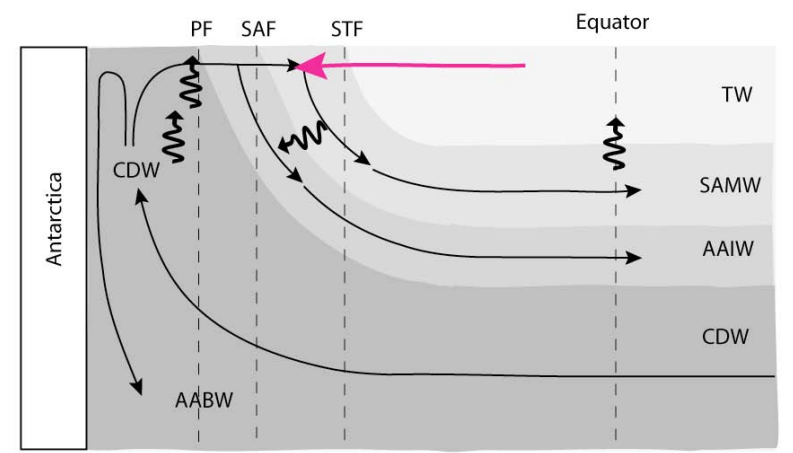

a)

b)

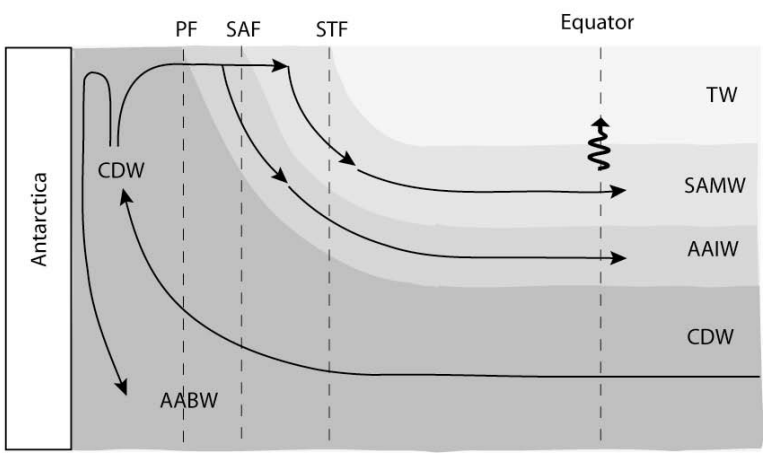

Fig. 2. Schematics of the overturning circulation in the Southern Ocean. Panel (a) accounts for both a major TW contribution to SAMW formation (e.g., Talley et al., 2003; Iudicone et al., 2008c) as well as a significant role for diapycnal transports below the base of the mixed layer in the upwelling of CDW over the Southern Ocean, due to small scale turbulence (e.g., Naveira Garabato et al., 2007) and cabbeling/thermobaricity (e.g., Iudicone et al., 2008a; Zika et al., 2009). Panel (b) assumes that CDW is the primary source for both AAIW and SAMW, and that transformations between these water masses are dominated by processes occurring in the mixed layer (e.g., Anderson et al., 2009).

However, in the current literature a consensus view of overturning circulation in this region does not yet exist as to the formation processes and ventilation pathways of some of the important water masses in this schematic. As a more specific illustration, we consider in Fig. 2a set of two schematics showing the overturning circulation of the Southern Ocean. These differ in important respects in the differences in implied formation pathways for SAMW and AAIW. For Fig. 2a, the formation of SAMW is assumed to have a contribution from subtropical thermocline water (TW), with internal mixing also contributing to the formation of SAMW and AAIW. This view is largely consistent with the view proposed by McCartney (1997), Talley et al. (2003) and Sallée et al. (2006), which invoked densification of TW as making an important contribution to the formation of Pacific and Indian SAMW, respectively.

Figure $2 b$, on the other hand, puts largely exclusive emphasis on the water mass transformations that occur dur- ing the northward surface Ekman flow of recently upwelled CDW water. Within this view, the transformations are driven by surface buoyancy fluxes. This view is widely invoked in ocean biogeochemistry literature (Sarmiento et al., 2004) as well as in paleo-oceanographic literature (Anderson et al., 2009). Importantly, this schematic of formation pathways has implicit in it several assumptions about what sets the preformed carbon and nutrient concentrations in SAMW. Given the importance of SAMW in supplying the surface waters in the low-latitudes with nutrients (Sarmiento et al., 2004), it is of critical important to better understand the formation process for this watermass.

One of our goals here is to identify which of these schematics is more plausible based on a state-of-the-art physical circulation model of the ocean, and to evaluate the implications for the Southern Ocean controls on the global ocean carbon cycle. Our intention is to present a new method that permits doing this quantitatively. The important questions to be addressed include:

- Which of the schematics presented in Fig. 2 best represent the large-scale overturning patterns that can impact the export of DIC across $30^{\circ} \mathrm{S}$ by SAMW and AAIW?

- What is the export rate of natural (pre-anthropogenic) carbon across $30^{\circ} \mathrm{S}$ by density class?

- For carbon, what are the relative roles of physical transformations, gas exchange, and biology in setting the northward export of DIC across $30^{\circ} \mathrm{S}$ by density class? and

- What is the role of diffusion in the large-scale controls on the Southern Ocean carbon cycle? It is our hope that a quantitative process understanding of the large-scale controls on carbon export for the pre-industrial steadystate will contribute to our process-understanding of the how climate change may impact the partitioning of carbon between the oceanic and atmospheric reservoirs.

These questions are scientifically interesting and important themselves. They will also serve as a step towards developing process-understanding that can be applied to infer the role of the Southern Ocean carbon cycle under climate change. Le Quéré et al. (2007) have argued that perturbations to the natural carbon cycle in this region are critical to global carbon/climate feedback, and this further underscores the importance of understanding the unperturbed natural carbon cycle in this region. Our investigation of the unperturbed natural carbon cycle makes use of a cyclostationary (seasonally varying) global ocean circulation model. The modeling configuration we use consists of the OPA circulation model, and the PISCES biogeochemistry model. The components of this modeling configuration are constantly evolving as new parameterizations are developed and tested. We have chosen here to use the circulation state that has been previously considered in a number of publications (including Iudicone 
et al., 2007; Iudicone et al., 2008a, b, c). Likewise we use the published version of the PISCES model (Aumont and Bopp, 2006). The advantage of this configuration is that the behavior and biases of this model configuration are well known.

To analyse the role of water mass transformation on the ocean carbon cycle, we appropriate here both Eulerian and Lagrangian diagnostic tools that have been developed to understand the physical circulation of the ocean. More specifically, the work here serves as an extension of the results presented by Iudicone et al. (2008a, b, c). The Eulerian and Lagrangian diagnostics are particularly well-suited to our interest in developing a density framework for this study, and their purpose is to provide process-understanding for the relative contributions of biology, advective transport, surface modifications, and interior mixing to the oceanic carbon cycle. We first show how a three-dimensional Lagrangian analysis can quantify the transports associated to the main overturning pathways. We then analyze in an Eulerian water mass framework how carbon is redistributed by water masses transformations, and how the different mechanisms concentrating/diluting inorganic carbon can modulate the net transport and the concentrations at $30^{\circ} \mathrm{S}$. The results are perfectly general for studying oceanographic problems, but the application we have chosen here is the Southern Ocean. Finally, the results are discussed in a specific section, and this is followed by the conclusions.

\section{Methods}

For this study, we use climatologically-varying threedimensional physical state fields from a 1500 year spinup of the global coupled ice-ocean model ORCA2-LIM. The climatologically varying physical state fields are used to drive offline a three-dimensional simulation with the Pelagic Interaction Scheme for Carbon and Ecosystem Studies (PISCES) biogeochemistry model. We shall henceforth refer to the model configuration used here as ORCA2-LIM-PISCES. The model specifics are described in more detail in the Appendix.

The bi-weekly mean three-dimensional circulation fields along with temperature, salinity, and vertical and horizontal mixing were saved from the circulation model. These biweekly fields were used to drive the PISCES model (Aumont and Bopp, 2006) offline, where it was spun up for 10000 years until convergence in the modeled oceanic carbon cycle was identified.

Within the equations of the PISCES model, DIC concentrations are impacted by a number of sources and sinks, in addition to advection and diffusion, for each time step. These include air-sea gas exchange, biology (primary productivity and respiration), and $\mathrm{CaCO}_{3}$ production/destruction. In addition to saving the bi-weekly mean DIC fields for the full model grid, we have also saved the bi-weekly means of the contributions associated with these different processes.
These fields are commonly referred to as the tendency terms, and these constitute the basis for the Eulerian set of diagnostics, since having the tendency terms facilitates our evaluation of the contributions of these processes to changes in DIC over the seasonal cycle in the model.

The analysis of the model output will be based on two quantitative approaches, referred as the Lagrangian and the Eulerain approaches. This study uses Lagrangian trajectory analysis (presented in Sect. 3.1) to characterize the largescale overturning circulation. Lagrangian trajectories facilitate a characterization of the large-scale overturning circulation in addition to the transformations that are associated with the large-scale circulation of the Southern Ocean. The Eulerian method, presented in Sect. 4, is based on previous theoretical results on the analysis of water mass transformations. It is extended here to the analysis of the tracer fields, and specifically, for characterizing the coupling between the oceanic overturning and the dynamical processes controlling the tracer distributions.

We wish to emphasize that this state-of-the-art model has a number of biases that are characteristic of all global ocean biogeochemistry models, especially those that include alkalinity as a prognostic tracer (described in more detail in the Appendix). Our goal here is not to claim that the model run presented is best understood as a perfectly realistic simulation of global biogeochemistry. Rather, the model is meant to be considered as a tool for understanding processes, which will provide a framework that we hope will prove useful to a wide range of oceanographic applications.

\section{A three-dimensional (Lagrangian) analysis of overturning}

A (volume-preserving) Lagrangian framework is ideal for the tracing of water masses as it allows for a quantitative analysis of the water masses redistribution by the ocean circulation. This method was first proposed by (Döös, 1995) and (Blanke and Raynaud, 1997) for the analysis of the ocean circulation and it was further developed in the context of the EU Project TRACMASS (http://doos.misu.su.se/ tracmass/tracmassproject/index.html). It traces the streamtubes of the complex velocity field and it is suitable, importantly, for correctly depicting the Southern Ocean meridional overturning circulation (e.g., Döös et al., 2008). The method is based on a analytical solution of the water parcel trajectory within the model gridbox, and has been used in about one hundred studies, mostly focussing on tracing the thermohaline circulation in GCM. It was first applied to the interpretation of passive tracers in the ocean by Rodgers et al. (2004) and Radenac et al. (2005).

When applying Lagrangian trajectory analysis to ocean models, one typically chooses a vertically-oriented surface in the ocean interior and releases many thousands of individual particles, with the understanding that each particle represents 
Table 1. Definition of water masses used in the text. Acronyms are: Thermocline water (TW), Mode Water (SAMW), Intermediate Water (AAIW), Upper Circumpolar Water (UCDW), Lower Circumpolar Water (LCDW) and Antarctic Bottom Water (AABW). The neutral density values of the boundaries between water masses have been defined on the base of a detailed analysis of the model physical fields (Iudicone et al., 2008a). Notice, in particular, that the model AAIW is cooler and thus denser than climatological in situ values.

\begin{tabular}{lc}
\hline Water masses & $\gamma$ \\
\hline TW & $20-26.0$ \\
SAMW & $26.0-27.2$ \\
AAIW & $27.2-27.8$ \\
UCDW & $27.8-28.0$ \\
LCDW & $28.0-28.2$ \\
AABW & $28.2-$ Bottom \\
\hline
\end{tabular}

a finite volume of water that is conserved along the model streamlines of flow (Blanke and Raynaud, 1997). Here we extend the same method to evaluate the pathways by which DIC is transported and distributed in three dimensions (referenced to crossings at $30^{\circ} \mathrm{S}$ ) by multipling $\phi_{i}$, the transport per water parcel $i$, by the DIC value at its final position.

Here we used the ARIANE version of the algorithm (http: //www.univ-brest.fr/lpo/ariane/; Blanke and Raynaud, 1997). As in the study of Iudicone et al. (2008a), here particles (about 800000 of them) are released into the seasonallyvarying model flow fields at $30^{\circ} \mathrm{S}$ where the flow is southward, and then stopped when they cross $30^{\circ} \mathrm{S}$ heading northward. The Lagrangian trajectories are computed off-line using bi-weekly circulation fields from the climatologicallyvarying ocean circulation fields. As we are interested in the full velocity fields that act on tracers, the velocities used include the bolus velocities calculated from the parameterization of Gent and McWilliams (1990) used in the model.

The Lagrangian analysis of the overturning, and its impact on oceanic carbon, is considered in the following two subsections. For both cases, we define our reference surface in the ocean to be $30^{\circ} \mathrm{S}$, and pose the question of what the large-scale transports and transformations are for water parcels that enter and then subsequently exit the Southern Ocean at $30^{\circ} \mathrm{S}$. For example, for SAMW that is exported northward across $30^{\circ} \mathrm{S}$ from the Southern Ocean, what are the source water masses? And what are the implications for the global ocean carbon cycle? Likewise, one can ask the same questions about AAIW as well as for CDW. It is important to keep in mind that although we focus primarily on SAMW and AAIW exported from the Southern Ocean, the method itself is perfectly general.

\subsection{Physical overturning and transformation}

We consider here the meridional overturning for the model, binned by the density classes listed in Table 1, except that UCDW and LCDW are considered together to represent CDW. The overturning circulation for the Southern Ocean as revealed by the Lagrangian diagnostics is illustrated in Fig. 3a This is effectively the same information that was presented in the overturning schematic in Fig. 6 of Iudicone et al., 2008c. Transports are shown in units of Sverdrups, with zonal integrals having been performed by water mass (the water masses are detailed in Table 1). The overturning here is referenced to $30^{\circ} \mathrm{S}$, as the aim was to characterize the global thermohaline circulation from a Southern Ocean perspective.

The earlier study of Iudicone et al. (2008c) detailed the pathways of interbasin exchange via the Southern Ocean and the associated water mass transformations. Here the same approach is used to investigate the pathways of the DIC transport and redistribution in the Southern Ocean. Transports associated with a transfer of dense to light waters are shown in red, and transports characterized by a densification are shown in blue. For each of the water masses, budgets referenced to $30^{\circ} \mathrm{S}$ are tabulated along the right side of the panel while the numbers adjacent to the arrows marking pathways correspond to the physical transports. The budgets are for the following quantities: the total northward transport $(\mathrm{N})$, the component of the northward transport that is recirculated within the density layer $(\mathrm{R})$, the component of the northward transport that entered the Southern Ocean in a different density class (O, for overturning), and the total southward transport $(\mathrm{S})$. The net export, discussed in the following sections, is thereby the difference between the northward and southward transports. Finally, for sake of clarity, here we will not discuss the three-dimensional structure of the pathways, descibed in Iudicone et al. (2008c).

Here we summarize the salient points regarding transformations that can be inferred from Fig. 3. First, the overturning explains about $35 \%$ of the transport across $30^{\circ} \mathrm{S}$, the remainder consisting of recirculation within the same layer. Further, a dominant process with the overturning circulation of the Southern Ocean is the consumption of CDW that enters the domain by flowing Southward across $30^{\circ} \mathrm{S}$. Within the Southern Ocean, the fate of Southward flowing CDW is split between the formation of AABW (almost $9 \mathrm{~Sv}$ ) and the export of lighter water masses $(11.7 \mathrm{~Sv})$. Part of the lightening (mostly via a freshwater gain) occurs through surface layer modifications, with this contributing to AAIW export (3.4 Sv), SAMW export $(8.5 \mathrm{~Sv})$, and through further lightening to export of TW (5.9 Sv). Some of this lightened export also benefits from lightening of upwelled AAIW (4.3 Sv) and upwelled SAMW (1.8 Sv). These changes are modulated by interior transports (below the base of the winter mixed layer) that are associated with internal mixing processes. These include a SAMW contribution to AAIW export of 7.4 Sv, and an AAIW contribution to the export of CDW of $2.2 \mathrm{~Sv}$. 
Importantly, it can be seen that there is a substantial contribution to SAMW export across $30^{\circ} \mathrm{S}$ from the transformation of TW to SAMW $(20.5 \mathrm{~Sv})$. This diapycnal transport associated with densification of TW is larger than the diapycnal transport associated with lightening of deeper waters to feed SAMW export. SAMW forms in a region of deep mixed layers, north of the subantarctic front, and thus our diagnostics are consistent with the interpretation of an important contribution of recently cooled TW to the SAMW formation process. The overturning diagnostics thus reveal that the model sources for the formation and export of SAMW (dominated by the $70 \%$ TW contribution) are more consistent with the interpretation of Talley et al. (2003) than with the schematic of Sarmiento et al. (2004) or Anderson et al. (2009). In other words, the interpretation offered here is more consistent with the circulation schematic shown in Fig. 2a than it is for the schematic shown in Fig. 2b.

The net volume export of AAIW from the Southern Ocean from Fig. 3 is about $4 \mathrm{~Sv}$. This value seems quite small, but is consistent with the export of AAIW inferred from data-based inversion calculations (see also Sloyan and Rintoul, 2001). For AAIW, it can be seen that the formation and export is not dominated by surface freshening of recently upwelled CDW water. Rather, interior transformations and densification of SAMW play first-order roles in the export of AAIW across $30^{\circ} \mathrm{S}$. Thus not only for SAMW but also for AAIW the formation pathways implied here (Fig. 2b) are very different from the view presented by Sarmiento et al. (2004) and Anderson et al. (2009). In the following section, we will explore the implications of these overturning schematics and transformation rates for DIC export across $30^{\circ} \mathrm{S}$.

\subsection{Carbon overturning and transformation}

The corresponding overturning transports for DIC are shown in Fig. 3b. They have been calculated by multiplying the DIC concentrations by the physical transport fields. As the concentration of DIC only varies by at most $10 \%$ over this domain, the transports of DIC (in units of $\mathrm{PgC}^{-1}$ ) are approximately equal to the fields shown in Fig. 3a multiplied by a factor of 0.8 . The figure reveals that to first order, CDW and TW provide a net supply of DIC to the Southern Ocean, and AABW, AAIW, and SAMW largely contributing to the northward export across $30^{\circ} \mathrm{S}$.

SAMW serves as the principal water mass responsible for the export of DIC across $30^{\circ} \mathrm{S}$, with the northward transport of 59.4 $\mathrm{PgC} \mathrm{yr}^{-1}$ therefore largely exceeding the southward transport. The single largest contribution to the export of SAMW results from the densification of TW $\left(16.3 \mathrm{Pg} \mathrm{Cyr}^{-1}\right)$. This is complemented by the contribution from denser water masses of $6.8 \mathrm{PgC} \mathrm{yr}^{-1}$. In order to appreciate the magnitude of this transport, one should one should consider it within the context of estimates of the current rate of uptake of anthropogenic carbon the the global ocean, which are of order $2.3 \mathrm{Pg} \mathrm{yr}^{-1}$ (Khatiwala et al.,
2009). For natural (pre-anthropogenic) DIC, the northward transport across $30^{\circ} \mathrm{S}$ by the SAMW density class is of order 25 or 30 times larger. In particular, the DIC in SAMW of TW origin (formed through densification) exported across $30^{\circ} \mathrm{S}$ is of order $6-8$ times the amplitude of the global ocean uptake rate for anthropogenic carbon.

The origin of the AAIW that flows across $30^{\circ} \mathrm{S}$ is largely recirculation. Rather surprisingly, the net export is very small relative to the export associated with SAMW. The contribution to the net DIC export in AAIW results principally from the overturning circulation (of order two-thirds from the downwelling of SAMW, and one-third due to upwelling of CDW). As was shown in Iudicone et al. (2008b), the densification of SAMW is due to the combined effects of surface buoyancy fluxes, and a range of mixing processes including cabbeling. The CDW is the great importer of DIC toward the Southern Ocean. In fact, the Southern Ocean acts as a powerful converter of CDW (e.g., Sloyan and Rintoul, 2001; Iudicone et al., 2008a) since CDW are intensely transformed, partly feeding the AABW and partly feeding the AAIW, the SAMW and the TW.

\section{The dynamical evolution of a tracer in a water mass framework}

Thus far we have presented a method for quantifying the large-scale overturning of the Southern Ocean, and described the integrated rates of import and export of different water masses across $30^{\circ} \mathrm{S}$, along with the integrated diapycnal flux of DIC referenced to $30^{\circ} \mathrm{S}$. We wish here to build on the large-scale Lagrangian description of transports of DIC (Fig. 3) with an analysis of the the DIC transport associated with the water mass transformations. With the DIC transport given by water mass transformations, we intend to characterize the effective diapycnal transport (in a density framework) of carbon experienced by a parcel of water that undergoes a modification from its original density through a dynamical process. Therefore, for process understanding, we now wish to distinguish between the model mechanisms that contribute to the diapycnal transport of DIC within this domain. The contending mechanisms that can contribute to this diapycnal transport include surface buoyancy fluxes, lateral (including cabelling and thermobaricity) and vertical mixing of density or buoyancy, and geothermal fluxes. As an example, we consider the case of a relatively warm water parcel that undergoes densification in winter through the loss of heat to the atmosphere in a western boundary current and is consequently transformed from a TW to a SAMW density class. Within this framework, the carbon within that water parcel would experience a diapycnal transport to a denser water mass. 

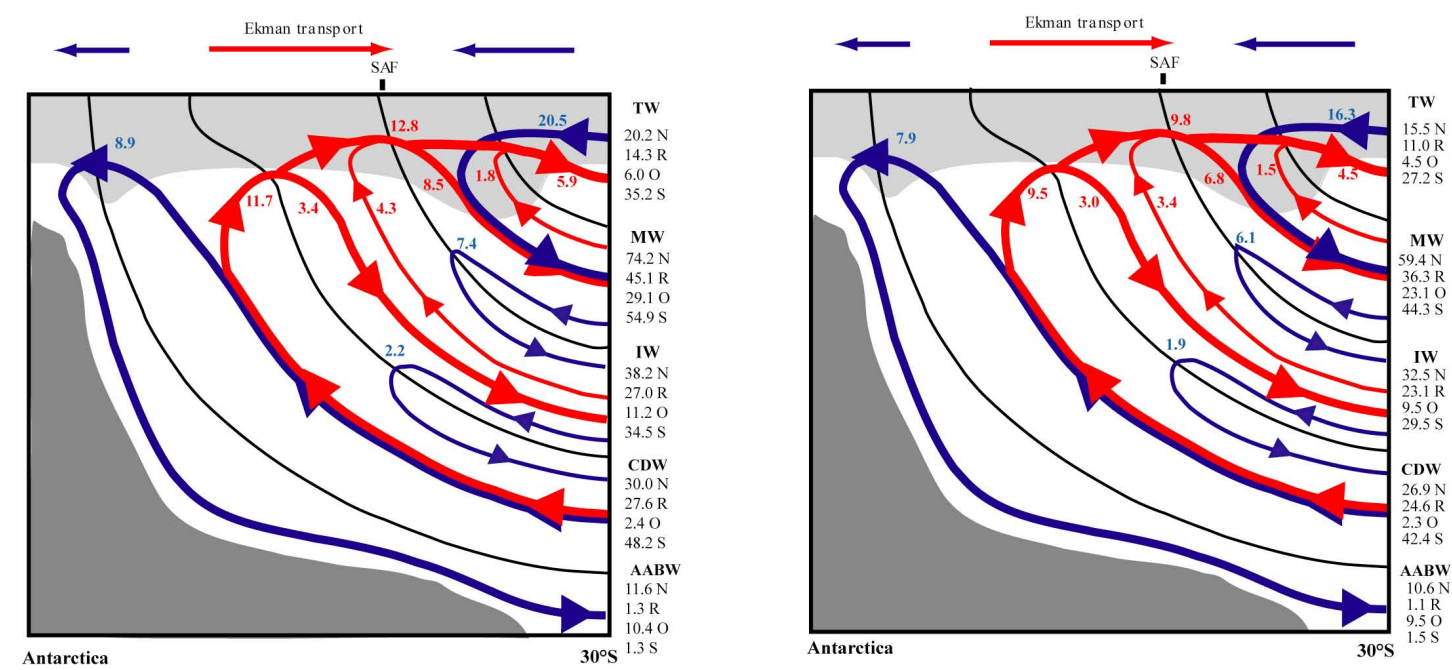

Fig. 3. A sketch of the overturning circulation in the Southern Ocean in the ice-ocean model with the main water mass transformations. For sake of simplicity, the recirculation is not graphically represented as well as the transformations less important. Further, the UCDW and LCDW has been merged into a unique CDW layer. The numbers along the vertical column correspond to: the total northward transport $(\mathrm{N})$, the component of the northward transport that recirculated within the isopycnal layer (R), the component of the northward transport water at the origin was in a different density class (overturning; O) and total southward transport (S). Left panel: Volume transport (Sv). Right panel: DIC transport ( $\mathrm{Pg} \mathrm{C} \mathrm{yr}^{-1}$ ) associated to the different branches of the overturning. The numbers correspond to the gain (positive values) or loss (negative values) of DIC.

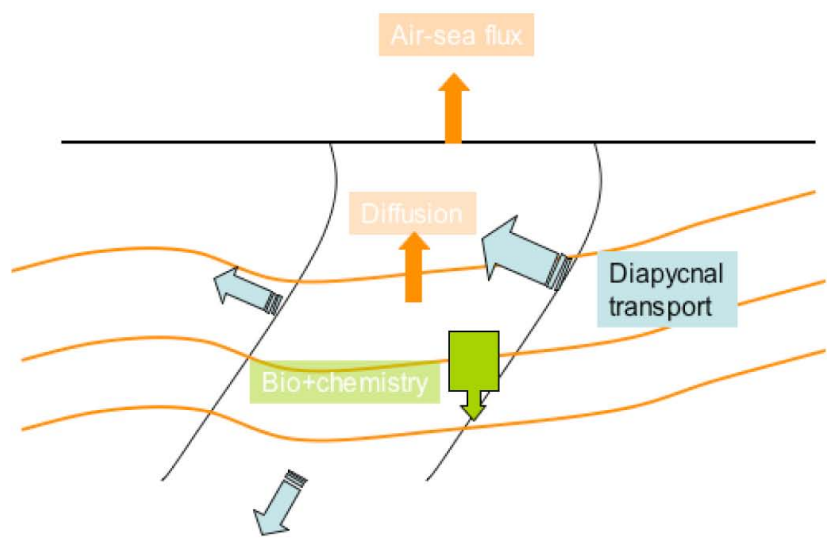

Fig. 4. Sketch of a tracer $\mathrm{C}$ balance in an isopycnal framework. Light blue arrowes indicate the advective contributions.

\subsection{Theory}

\subsubsection{The water mass framework}

Here we extend the classical water mass diagnostics of the impact of physical terms on the diapycnal fluxes (initiated by Walin, 1982; see also Nurser et al., 1999, and Marshall et al., 1999) to derive a tool for the quantitative analysis of factors (advection and sources/sinks) that determine tracer transport across a particular oceanic boundary (e.g., the boundary of a particular basin) (see Fig. 4).
More specifically, within our water mass framework we want to compute the budget of the divergence/convergence of the tracer given by diapycnal transport across the isopycnals separating the water masses, decompose this into the different processes sustaining the diapycnal transport, and compare it with sources/sinks that are distinct form physical transformation processes. As a starting point we will review the generalized approach for the evaluation of diapycnal transports presented in Iudicone et al. (2008b), which introduced the use of neutral density (Jackett and McDougall, 1997) and a term which considers the effect of the penetration of solar radiation into the upper layers of the ocean.

A schematic for the framework we will use is shown in Fig. 5. Given a volume $V_{\gamma}$ of water bounded by the ocean bottom, the ocean surface, one isopycnal surface $S_{\gamma}$ and an open boundary $\mathrm{OB}_{\gamma}$, the aim is first to evaluate the volume transport across the isopycnal surface. For the sake of clarity, here we assume the volume transport at the surface is negligible even if it is fully considered by the diagnostics (see Iudicone et al., 2008b). The following formulations are valid for any density variable, including neutral density, which is the one applied here. In the results sections we will use the generic term "density" while referring to neutral density. The use of neutral density, which indeed complicates the actual computation (Iudicone et al., 2008b), represents an important step forward as it allows one to correctly quantify the ensemble of processes occurring from the surface to the ocean bottom. This is in fact not possible for any density coordinate that depends on a reference depth, such as potential density. 
The equation of evolution of the density $\gamma$ is $D \gamma / D t=$ $d_{\gamma}+f_{\gamma}$ where $d_{\gamma}$ represents the mixing processes (vertical and lateral (eddy) diffusive processes and bottom layers turbulence) and $f_{\gamma}$ are the boundary buoyancy forcing (air-sea and ice-sea interactions, geothermal flux) acting on the density evolution. (In practice, these terms are evaluated in terms of non-advective processes and external forcing acting on temperature and salinity.) We introduce two scalar quantities, $\omega_{\gamma}$ and $|\nabla \gamma|$, defined as the velocity across the moving $S_{\gamma}$ and the modulus of the gradient of $\gamma$ (by definition it has a direction normal to $S_{\gamma}$ ). In this framework, the material derivative of $\gamma, \frac{D \gamma}{D t} \equiv \frac{\partial \gamma}{\partial t}+\mathbf{u} \cdot \nabla \gamma$, reduces to the product $\omega_{\gamma}|\nabla \gamma|$. Using the latter expression, we can define

$\omega_{\gamma}=\left(d_{\gamma}+f_{\gamma}\right)|\nabla \gamma|^{-1}$

as the diapycnal velocity across the moving $S_{\gamma}$. Thus, the total volume transport across the isopycnal surface $S_{\gamma}$ can be represented as

$$
\begin{aligned}
\Omega_{\gamma} & =\int_{S_{\gamma}} \omega_{\gamma} d s \\
& =\int_{S_{\gamma}}\left(d_{\gamma}+f_{\gamma}\right)|\nabla \gamma|^{-1} d s \\
& =\frac{\partial}{\partial \gamma} \int_{V_{\gamma}} d_{\gamma} d v+\frac{\partial}{\partial \gamma} \int_{V_{\gamma}} f_{\gamma} d v
\end{aligned}
$$

where the latter step was made making use of a generalized form of Leibnitz's theorem. One should note that the lateral (isoneutral) diffusive processes can give rise to net diapycnal transports due to the non-linearity of the equation of state, via processes as cabbeling and thermobaricity (McDougall, 1987). It is also worth noting that only the use of neutral density allows for a correct evaluation of the latter terms.

\subsubsection{The tracer evolution}

The expression above will serve as starting point for the evaluation of the tracer transports. Consider the ocean volume delimited by an open boundary, the ocean surface and an isopycnal $\gamma$ (Fig. 5) as being filled with a tracer whose inventory (or stock) is $C=\int_{V_{\gamma}} c d v$ where $c=c(x, y, z, t)$ is a local concentration per unit volume. (Note that the reasoning that follows is also valid for a concentration expressed per unit mass.). Assume that the tracer $c$ is transported by the flow, that it is exposed to diffusive processes $d_{c}$ and that it is reactive, i.e., it has sources and sinks $\pi_{c}$ such has that its time evolution is:

$$
\frac{D c}{D t} \equiv \frac{\partial c}{\partial t}+\mathbf{u} \cdot \nabla c=d_{c}+\pi_{c} .
$$

First, we express the rate of change the integrated quantity as the sum of the integral of the local derivative and the contribution to the inventory from the inflation/deflation of the volume:

$\frac{d C}{d t} \equiv \frac{d}{d t} \int_{V_{\gamma}} c d v=\int_{V_{\gamma}} \frac{\partial c}{\partial t} d v+\int_{\partial V_{\gamma}} c \mathbf{u}_{S} \cdot \mathbf{n} d s$

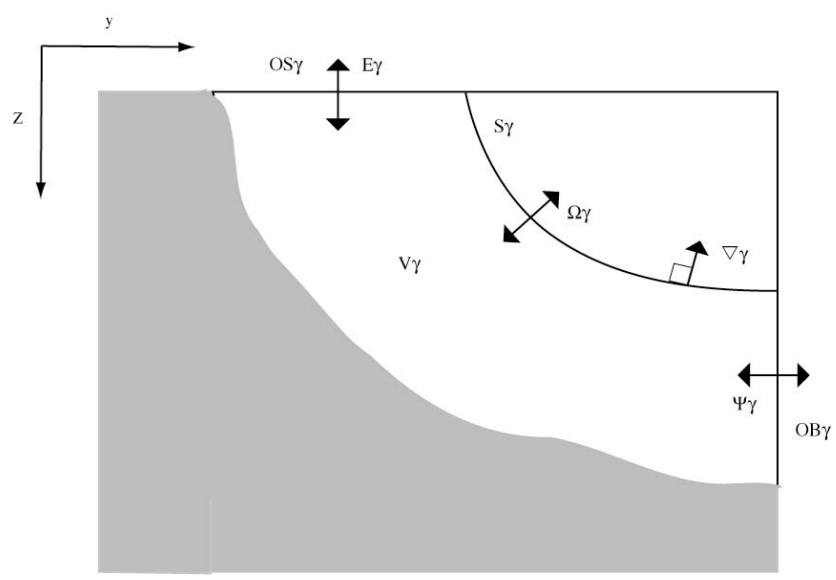

Fig. 5. Sketch of the ideal oceanic basin. We consider a limited area of the ocean with an open boundary. We denote $S_{\gamma}$, the surface with neutral density $\gamma$ over the limited domain; the volume $V_{\gamma}$ sandwiched between the isoneutral surfaces $S_{\gamma}$, the ocean bottom and the ocean surface $O S_{\gamma} ; \Psi_{\gamma}$ and $E_{\gamma}$ the volume fluxes of fluid entering/exiting the domain $V_{\gamma}$ across the open boundary $O B_{\gamma}$ and surface, resp.; and $\Omega_{\gamma}$, the total volume flux across the $S_{\gamma}$ (i.e. the dianeutral volume flux). The sign convention is that all the fluxes are positive if entering $V_{\gamma}$.

where $\mathbf{u}_{S}$ is the velocity of the isopycnal surface and $\partial V_{\gamma}$ is the boundary of $V$ (here $\partial V_{\gamma}=S_{\gamma}+\mathrm{OB}_{\gamma}$ ). Importantly $\frac{d}{d t}$ is used rather than $\frac{\partial}{\partial t}$ as there are no dependence on spatial variables. In other words, it is the time derivative of a volume integral over a time-varying reference volume.

Assuming incompressibility, invoking Gauss's theorem and using Eq. (4), we can rewrite the left hand terms of the integral over the volume $V_{\gamma}$ of Eq. (3) as

$$
\frac{d C}{d t}+\int_{S_{\gamma}} c \mathbf{u}_{r} \cdot \mathbf{n} d s+\int_{O B_{\gamma}} c \mathbf{u} \cdot \mathbf{n} d s
$$

where $\mathbf{u}_{r}$ is the velocity relative to the same surface (i.e., $\left.\mathbf{u}_{r}=\mathbf{u}-\mathbf{u}_{S}\right)$ and $\mathbf{u}_{r}=\mathbf{u}$ across $\mathrm{OB}_{\gamma}$. The first term is the desired quantity, the rate of change of the extensive quantity $C$ within the volume of water denser than $\gamma$, the second term is the transport across the isopycnal surface in the framework moving with the isopycnal and the last one is the transport at the open boundary.

Extending the results in Iudicone et al. (2008b), we now express explicitly the dianeutral transport of the tracer $\Phi_{\gamma}$ in terms of the ocean physics, i.e., the processes that act on transforming water masses, here divided into mixing processes $\left(d_{\gamma}\right)$ and boundary forcing $\left(f_{\gamma}\right)$. Using $\omega_{\gamma}=\left(d_{\gamma}+\right.$ $\left.f_{\gamma}\right)|\nabla \gamma|^{-1}$ (Eq. 1) as dianeutral velocity relative the moving $\partial V_{\gamma}$, the transport of $c$ per unit surface across a neutral density surface is given by

$\phi_{\gamma}=c \omega_{\gamma}=c\left(d_{\gamma}+f_{\gamma}\right)|\nabla \gamma|^{-1}$. 
Specifically, the tracer flux $\Phi_{\gamma}$ across the $S_{\gamma}$ is then:

$$
\begin{aligned}
\Phi_{\gamma} & \equiv \int_{\partial V_{\gamma}} c \omega_{\gamma} d s=\int_{\partial V_{\gamma}} c\left(d_{\gamma}+f_{\gamma}\right)|\nabla \gamma|^{-1} d s \\
& =\underbrace{\frac{\partial}{\partial \gamma} \int_{V_{\gamma}} c d_{\gamma} d v}_{\text {Diffusive buoyancy processes }}+\underbrace{\frac{\partial}{\partial \gamma} \int_{V_{\gamma}} c f_{\gamma} d v}_{\text {Surface buoyancy processes }}
\end{aligned}
$$

where the latter passage was made making use of a generalized form of Leibnitz's theorem.

Using the equivalence $\omega_{\gamma} \equiv \mathbf{u}_{r} \cdot \mathbf{n}$ and the expression above, one then has the expression for the rate of change of the extensive tracer value

$$
\begin{gathered}
\underbrace{\frac{d C}{d t}}_{\text {Tracerrate of change }}=-\underbrace{\left[\frac{\partial}{\partial \gamma} \int_{V_{\gamma}} c d_{\gamma} d v+\frac{\partial}{\partial \gamma} \int_{V_{\gamma}} c f_{\gamma} d v\right]}_{\text {watermass transformation }} \\
-\underbrace{\int_{B V_{\gamma}} c \mathbf{u} \cdot \mathbf{n} d s}_{\text {Transportatboundary }}+\underbrace{\int_{O S_{\gamma}} \phi_{a} d s}_{\text {Air-sea exchange }}+\underbrace{\int_{V_{\gamma}} d_{c} d v}_{\text {Diffusion }}+\underbrace{\int_{V_{\gamma}} \pi_{c} d v}_{\text {Internal sources/sinks }}
\end{gathered}
$$

All the terms in Eq. (9) can be estimated using the tendency terms for temperature and salinity (Iudicone et al., 2008b) and for the tracer field $c$. Practically, the diapycnal transport is computed by approximating the derivative of the volume integral of the tendency terms of density using a binning procedure (Iudicone et al., 2008b).

Next we consider two extreme cases as a means of illustration:

1. For the case of fixed isopycnal surfaces (steady state buoyancy processes and transient tracer dynamics) we have $\mathbf{u}_{S}=0$ and thus the rate of change of the tracer inventory (left hand term in Eq. 9) reduces to

$$
\frac{d C}{d t} \equiv \int_{V_{\gamma}} \frac{\partial c}{\partial t} d v
$$

If one considers the extreme case of a purely advected tracer (a passive tracer with zero sources and sinks and zero diffusion) Eq. (9) simply states that the rate of change of the tracer inventory is equal to the convergence of the tracer produced by the diapycnal transport at the (fixed) boundaries (i.e., by advection).

2. The tracer inventory change is determined only by the volume change. In this case

$$
\frac{d C}{d t} \equiv \int_{\partial V_{\gamma}} c \mathbf{u}_{S} \cdot \mathbf{n} d s
$$

In the even more extreme case of still water (null velocity field), with no processes acting on the tracer evolution, while at the same time permitting active thermodynamic processes (e.g., a warming of the layer by penetrative solar irradiance) the surface moves in response to the change in density and thus the tracer inventory changes due to the volume variation. In this case Eq. (9) reduces to

$$
\frac{d C}{d t}=-\underbrace{\frac{\partial}{\partial \gamma} \int_{V_{\gamma}} c\left(d_{\gamma}+f_{\gamma}\right) d v}_{\text {Buoyancy processes }}
$$

i.e., the effect of the inflating/deflating of the isopycnal volume by thermodynamic processes (e.g., heating or cabbeling) is fully retained (recalling that since $\mathbf{u}=0$, $\mathbf{u}_{r}=-\mathbf{u}_{S}$ ).

Finally, assuming a steady state $\left(\frac{d C}{d t}=0\right)$, or summing up over one cycle in a cyclo-stationary case $\left(\frac{d C}{d t}=0\right.$ over one cycle since the inventory is unchanged), the northward transport $\Psi_{\gamma}$ across the line of latitude $\theta=\Theta$ of the tracer by water masses denser than $\gamma\left(\Psi_{\gamma}=\int_{\mathrm{OB}_{\gamma}} \mathbf{u} \cdot \mathbf{n} d s\right.$ where $\mathbf{n}$ is the outward unit vector normal to the boundary at time $t$ ) can be expressed in terms of the total diapycnal tracer transport down across $\gamma$ south of $\theta=\Theta$ and the net effect of the sources and sinks of the tracer. Eq. (9) thus allows one to link the tracer evolution to the ocean physics in a simple and elegant way.

In such limiting cases, the integration of Eq. (9) from the South Pole to a latitude $\theta=\Theta$ gives

$\Psi_{\gamma}(\Theta) \sim \Phi_{\gamma}(\Theta)-A_{\gamma}(\Theta)+\Sigma_{\gamma}(\Theta)+\Pi_{\gamma}(\Theta)$.

The first term $\Phi_{\gamma}$ is the transport across the isopycnal surface defined above (Eq. 8), the second term $A_{\gamma}$ is the integrated air-sea flux of the tracer $c$, the third term $\Sigma_{\gamma}$ represents the net effect of the diffusion on the tracer and the last term $\Pi_{\gamma}$ is the volume integral of source and sinks (i.e., chemistry or biology) on the isoneutral layer. (The volume integral of the diffusive term is equivalent to evaluating the convergence/divergence of diffusive fluxes over the volume boundaries.) Since this approach can applied to any tracer and it includes all the dynamical processes involved in the tracer evolution, this in fact correspond to a possible generalization of generalized meridional heatfunction of Greatbatch and Zhai (2007) (see also Marsh et al., 2000; Iudicone et al., 2008b).

Finally it should be noted that even if the system is not in steady state, the use of Eq. (9) allows one to compare quantitatively the role of different processes acting on the evolution of any tracer. For example, the theoretical framework presented here allows one to dynamically relate changes in wind stress forcing and the subsequent response of the ocean carbon cycle to these perturbations. In other words, this framework would be perfectly appropriate for a dynamical interpretation of the carbon saturation mechanism for the Southern Ocean proposed by Le Quéré et al. (2007). It is also appropriate for investigating carbon/climate feedbacks for earth system model investigations of climate change scenarios. 


\subsubsection{Insights into tracer concentrations}

The balance allows one to also characterise the tracer properties of the outgoing flow of a given water mass (sandwiched between $\gamma_{a}$ and $\gamma_{b}$ ) across the open boundary $\mathrm{OB}_{\gamma_{a b}}$. If one defines the northward and southward volume transports at the boundary as, respectively:

$$
\begin{array}{ll}
\Psi_{\mathrm{OB}_{\gamma_{a b}}}^{\text {north }}=\int_{\mathrm{OB}_{\gamma_{a b}}} \mathbf{u} \cdot \mathbf{n} d s & \text { with } \quad \mathbf{u} \cdot \mathbf{n}>0 \\
\Psi_{\mathrm{OB}_{\gamma_{a b}}}^{\text {south }}=\int_{\mathrm{OB}_{\gamma_{a b}}} \mathbf{u} \cdot \mathbf{n} d s & \text { with } \quad \mathbf{u} \cdot \mathbf{n}<0
\end{array}
$$

then one can evaluate the transport-weighted tracer averages at the open boundary as

$$
\begin{aligned}
& <C>{ }_{\mathrm{OB}_{\gamma_{a b}}}^{\text {north }}=\int_{\mathrm{OB}_{\gamma_{a b}}} C \mathbf{u} \cdot \mathbf{n} d s / \Psi_{\mathrm{OB}_{\gamma_{a b}}}^{\text {north }} \quad \text { with } \quad \mathbf{u} \cdot \mathbf{n}>0 \\
& <C>>_{\mathrm{OB}_{\gamma_{a b}}}^{\text {south }}=\int_{\mathrm{OB}_{\gamma_{a b}}} C \mathbf{u} \cdot \mathbf{n} d s / \Psi_{\mathrm{OB}_{\gamma_{a b}}}^{\text {south }} \quad \text { with } \quad \mathbf{u} \cdot \mathbf{n}<0
\end{aligned}
$$

while the transport-weighted tracer average across a generic isoneutral surface $S_{\gamma}$ is simply the ratio between the tracer diapycnal transport and the volume diapycnal transport, i.e.,

$$
<C>_{S_{\gamma}}=\Phi_{\gamma} / \Omega_{\gamma}
$$

Using the definitions above and Eq. (13), the transportweighted average of the tracer transported by the outgoing flow at the boundary can be expressed in term of transports as

$$
\begin{aligned}
<C>{ }_{\mathrm{OB}_{\gamma_{a b}}}^{\text {north }} \sim & <C>{ }_{\mathrm{OB}_{\gamma_{a b}}}^{\text {south }} \Psi_{\mathrm{OB}_{\gamma_{a b}}}^{\text {south }} / \Psi_{\mathrm{OB}_{\gamma_{a b}}}^{\text {north }} \\
& +\Phi_{\gamma_{b}} / \Psi_{\mathrm{OB}_{\gamma_{a b}}}^{\text {north }} \\
& -\Phi_{\gamma_{a}} / \Psi_{\mathrm{OB}_{\gamma_{a b}}}^{\text {north }} \\
& +\Delta_{a b}\left(A_{\gamma}+\Sigma_{\gamma}+\Pi_{\gamma}\right) / \Psi_{\mathrm{OB}_{\gamma_{a b}}}^{\text {north }}
\end{aligned}
$$

where the latter term represents the volume integral of the tendency terms integrated over the isopycnal volume. The equation above can be explicitly written in terms of average concentrations of the tracer at the boundaries as

$$
\begin{aligned}
<C>{ }_{\mathrm{OB}_{\gamma_{a b}}}^{\text {north }} \sim & <C>{ }_{\mathrm{OB}_{\gamma_{a b}}}^{\text {south }} \Psi_{\mathrm{OB}_{\gamma_{a b}}}^{\text {south }} / \Psi_{\mathrm{OB}_{\gamma_{a b}}}^{\text {north }} \\
& +<C>s_{\gamma_{b}} \Omega_{\gamma_{b}} / \Psi_{\mathrm{OB}_{\gamma_{a b}}^{\text {north }}}^{\text {con }} \\
& -<C>s_{\gamma_{a}} \Omega_{\gamma_{a}} / \Psi_{\mathrm{OB}_{\gamma_{a b}}}^{\text {north }} \\
& +\Delta_{a b}\left(A_{\gamma}+\Sigma_{\gamma}+\Pi_{\gamma}\right) / \Psi_{\mathrm{OB}_{\gamma_{a b}}}^{\text {north }}
\end{aligned}
$$

Therefore, an inspection of the water mass budget allows one to evaluate the importance of the role of dianeutral transports (the overturning) with respect to recirculation in the same layer $\left(\Psi_{\mathrm{OB}_{\gamma a b}}^{\text {south }}\right)$ and sources and sinks in setting the outflow tracer characteristics.
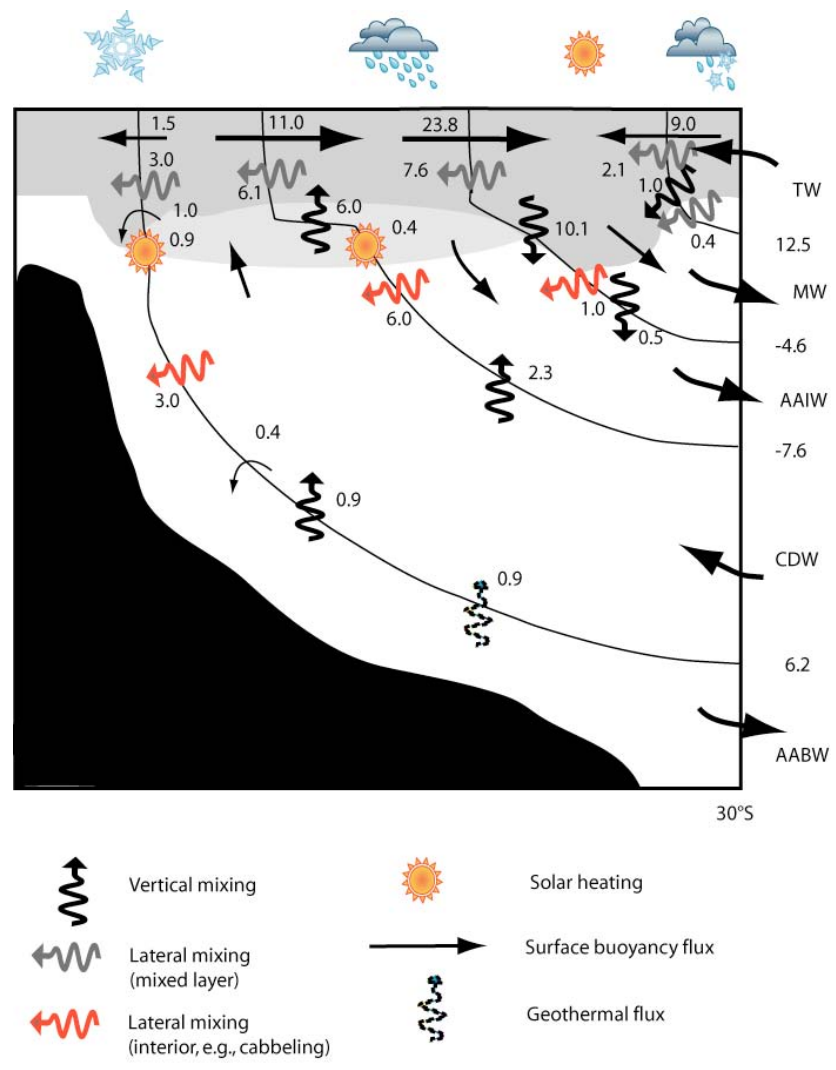

$$
\bigcap \text { Mixing in bottom boundary layers }
$$

Fig. 6. Sketch of the principal DIC dianeutral transports due to water mass transformations in the model. Units are in $\mathrm{PgC} \mathrm{yr}^{-1}$. Numbers on the right refer to the net dianeutral DIC transport (positive values correspond to transport toward larger densities). The dark shaded region is the region of annual maximum mixed layer depth while the light shaded region is the stratified region impacted by the solar heating. For a discussion of assumptions made in the computations in Iudicone et al. (2008a).

\section{The overturning and the DIC redistribution}

\subsection{The role of water masses transformations in setting the net northward transport of carbon}

The evaluation of $\Phi_{\gamma}$ (Eq. 8) from the ocean model run facilitates a quantification of the dianeutral DIC transports due to different process, with the different contributions shown in Fig. 6. Since the binning method used to evaluate the transports suffer from errors deriving from the discretization, the relatively low resolution of the model and the computation of the neutral density parameters (the $b$ factor) (see Discussion), the figures need to be interpreted as being relatively rough estimates, with an error that can be up to $1 \mathrm{PgC}^{-1}$ or more for the densest waters (Iudicone et al., 2008b).

\footnotetext{
${ }^{1}$ In fact, for the case of DIC, geographical variations are small $(\sim 1-10 \%)$ and thereby $\Phi_{\gamma}\left(\Theta=30^{\circ} \mathrm{S}\right)$ is roughly proportional to
} 
In constructing the budgets the domain has been subdivided into two layers, the bowl (as defined in Iudicone et al., 2008a, b) and the ocean interior, separated by the depth of the maximum winter mixed layer depth plus two vertical grid points. This choice for a surface of separation was intended to neatly separate upper boundary layer processes, directly related to the air-sea exchange of properties (momentum, buoyancy, etc.) from processes occurring in the interior, generally associated with different dynamics. Further, the use of a fixed surface allows one to consider the entrainment/detrainment processes (fully considered here) as part of the seasonal cycle of mixing in the upper layer. The addition of two grid points is motivated by the actual penetration of surface forcing effects (e.g., shear) below the mixed layer, i.e., into the generally defined transitional layer (e.g., Johnston and Rudnick, 2009) where turbulence intensity decreases from high values in the mixed layer to lower values in the interior. The aim is to not overestimate the role of deep diffusivities, not directly related to the wind forcing, when computing the role of mixing in the model ocean interior. A deeper boundary (with respect to the standard choice of the mixed layer depth) means also that we are actually underestimating here the role of the solar irradiance in the upwelling of the model dense waters.

Figure 6 highlights that, as discussed in Iudicone et al. (2008a), most of the diapycnal processes occur in relatively close proximity to the surface boundary layer of the ocean. In particular, SAMW production is associated with convergent surface buoyancy fluxes densifying TW (9.0 $\mathrm{Pg} \mathrm{C} \mathrm{yr}^{-1}$ ) and the corresponding lightening of AAIW (23.8 $\mathrm{Pg} \mathrm{C} \mathrm{yr}^{-1}$ ) with the latter being driven mainly by freshwater fluxes. This latter process is partially compensated by densification via lateral mixing with AAIW (7.6 $\mathrm{PgC} \mathrm{yr}^{-1}$ in the bowl and $1 \mathrm{PgC} \mathrm{yr}^{-1}$ in the interior), and vertical mixing of density (10.1 $\mathrm{Pg} \mathrm{C} \mathrm{yr}^{-1}$ at the base of the bowl and 0.5 $\mathrm{Pg} \mathrm{C} \mathrm{yr}^{-1}$ ). It is important to emphasize that the diapycnal transport of DIC due to buoyancy mixing described here is distinct from what one would attribute to diffusion through the advection/diffusion equation for DIC. The contribution due to the impact of vertical mixing on DIC will be discussed in the following section.

The principal water mass transformation that characterizes the Southern Ocean upwelling of CDW evidently occurs at the boundary between CDW and AAIW. The convergence of these fluxes with the fluxes at the AAIW-SAMW boundary serves to sustain the net AAIW production. The main process sustaining the lightening of CDW upon upwelling is a surface buoyancy gain (dominated by freshwater forcing), and this is associated with a transport of $11.0 \mathrm{Pg} \mathrm{C} \mathrm{yr}^{-1}$ into

the volume transport itself $\Psi_{\gamma}\left(\Theta=30^{\circ} \mathrm{S}\right)$ (with, roughly, $1 \mathrm{~Sv}$ corresponds to $0.8 \mathrm{Pg} \mathrm{C} \mathrm{yr}^{-1}$ ), discussed in Iudicone et al. (2008a). For this reason, only the main results will be summarized here, and the reader is left to Iudicone et al. (2008a) for details on the role of the different physical processes. the AAIW density class. For the transport of carbon from CDW to AAIW, this process is complemented by a transport of $6.0 \mathrm{Pg} \mathrm{C} \mathrm{yr}^{-1}$ from vertical mixing across the base of the mixed layer, and $2.3 \mathrm{PgC}^{-1}$ in the interior. Additionally, solar heating in the interior by itself contributes $0.4 \mathrm{Pg} \mathrm{C} \mathrm{yr}^{-1}$ of diapycnal transport of DIC from CDW to AAIW. These latter processes therefore contribute significantly to the upwelling of DIC, feeding the excess of DIC in the AAIW outcrop area.

These transports that contribute to the DIC transfer from the upwelled CDW are partially compensated by 12.1 $\mathrm{Pg} \mathrm{C} \mathrm{yr}^{-1}$ (6.1 $\mathrm{PgC} \mathrm{yr}^{-1}$ in the bowl and 6.0 $\mathrm{PgC} \mathrm{yr}^{-1}$ in the interior) of lateral mixing from AAIW to CDW density classes, with part of this being associated with cabbeling. Several processes contribute to the diapycnal supply of DIC in AABW formation, including the bottom mixing occurring in the cascading currents along Antarctica. Interestingly, geothermal heating is comparable to the deep vertical mixing in contrasting the AABW formation. Lateral mixing processes provide a contribution of $3.0 \mathrm{PgC} \mathrm{yr}^{-1}$ in the in-

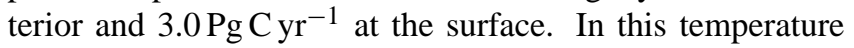
range, thermobaricity is clearly important. Considering the low rate of dense water formation in the model (as in most models at this resolution) it is quite likely to be underestimated.

In summary, the buoyancy gain experienced at the surface during Ekman transport promotes a large export of DIC northward across $30^{\circ} \mathrm{S}$ and across isopycnals. The contribution of mixing is complex, as in some respects it promotes the diapycnal transport of DIC and supports the northward net export associated with the meridional overturning, and in other respects it acts to diminish it.

\subsection{The overturning and the DIC sources and sinks}

Thus far, we have focused largely on a characterization of the pathways of DIC transport through its connection to the large-scale overturning of the ocean. Next we turn our attention to quantifying and understanding the specific processes that act as sources and sinks of DIC over the Southern Ocean. We start by posing a question: For the large-scale diapycnal transports of DIC evident in Fig. 6, what are the corresponding sources and sinks of DIC that modulate the concentrations for the different water masses?

Our objective here is first to provide an integrated view of the changes that occur along the pathways within the region south of $30^{\circ} \mathrm{S}$. We know water parcel DIC concentrations at their point of entry into and departure from the Southern Ocean (referenced to $30^{\circ} \mathrm{S}$ ), and we also have knowledge of the large-scale circulation pathways that connect the point of entry to the point of departure. Thus, we can quantitatively estimate sources and sinks of DIC for each pathway. The strength of this approach is that it is general, and fully accounts for the case of a parcel experiencing water 
mass transformations across multiple density classes during its journey through the domain.

The DIC sources and sinks were obtained by computing the equivalent dilution/concentration values, i.e. as $\triangle \mathrm{DIC} *$ $\phi_{i}=\left(\mathrm{DIC}_{\text {out }}-\mathrm{DIC}_{\mathrm{in}}\right) \phi_{i}$ where $\mathrm{DIC}_{\text {out }}\left(\mathrm{DIC}_{\mathrm{in}}\right)$ are the $\mathrm{DIC}$ values at the moment of leaving (entering) the Southern Ocean at the reference section while $\phi_{i}$ is the volume transport per particle which, importantly, is conserved along the trajectory by construction (Blanke and Raynaud, 1997). In fact, the latter property makes this method a quantitative one. Finally, the transports per trajectory were summed and partitioned into water masses using the density at their final position. (A similar approach has been used to evaluate buoyancy gains/losses in the upwelling of CDW in the study of Iudicone et al., 2008c.)

The result of the computation of along-pathway sources and sinks is presented in Fig. 7. This provides a basis for a direct comparison for the relative impacts of the transports of DIC associated with the overturning that were shown in Fig. 3. The first result of this comparison is that the net exchange of DIC across $30^{\circ} \mathrm{S}$ is dominated by the overturning circulation. In comparing the lower panel of Fig. 7 with Fig. 3, it is immediately clear that the sources and sinks of DIC along the paths have amplitudes that are everywhere less than $10 \%$ of the amplitude of the transports, and in general the sources and sinks are significantly less than $10 \%$ than the net transports. In other words, although the combined effects of diffusion, gas exchange, the biological pump (primary production, $\mathrm{P}$, and remineralization, $\mathrm{R}$ ), and $\mathrm{CaCO}_{3}$ production/destruction do impose non-trivial modifications onto the carbon exchange across $30^{\circ} \mathrm{S}$ by density class, their impact is simply overwhelmed by the enormity of the diapycnal transports associated with the large-scale overturning circulation. Further, even though in some cases single processes are locally important, there is a tendency for these processes to compensate when integrated over the water mass layers. We will evaluate this in more detail in the following section.

The dominance of transport is distinctly clear for the case of SAMW (the main exporter of DIC from the Southern Ocean), where the northward export of $59.4 \mathrm{Pg} \mathrm{C} \mathrm{yr}^{-1}$ across $30^{\circ} \mathrm{S}$ through transport is only reduced by $0.13 \mathrm{Pg} \mathrm{C} \mathrm{yr}^{-1}$ through the combined effects of the sources and sinks listed above. The SAMW component with origins as CDW and AAIW loses DIC $\left(-0.53 \mathrm{Pg} \mathrm{C} \mathrm{yr}^{-1}\right)$, while the SAMW component with TW origins gains DIC during transformation (0.38 $\mathrm{Pg} \mathrm{C} \mathrm{yr}^{-1}$; mostly by air-sea fluxes and diffusive processes) but this gain is smaller than the loss of DIC.

It is also evident for the case of AAIW, with a northward transport of $32.5 \mathrm{Pg} \mathrm{C} \mathrm{yr}^{-1}$ having only an additional contribution of $0.03 \mathrm{Pg} \mathrm{C} \mathrm{yr}^{-1}$ from the sources and sinks along the pathway. As we have seen for AAIW, this overturning transport of DIC results mainly from the densification of SAMW. The origin of the AABW that leaves the Southern Ocean at $30^{\circ} \mathrm{S}$ is primarily the CDW. This water mass exports DIC towards the north, but the northward flux of the AABW gains

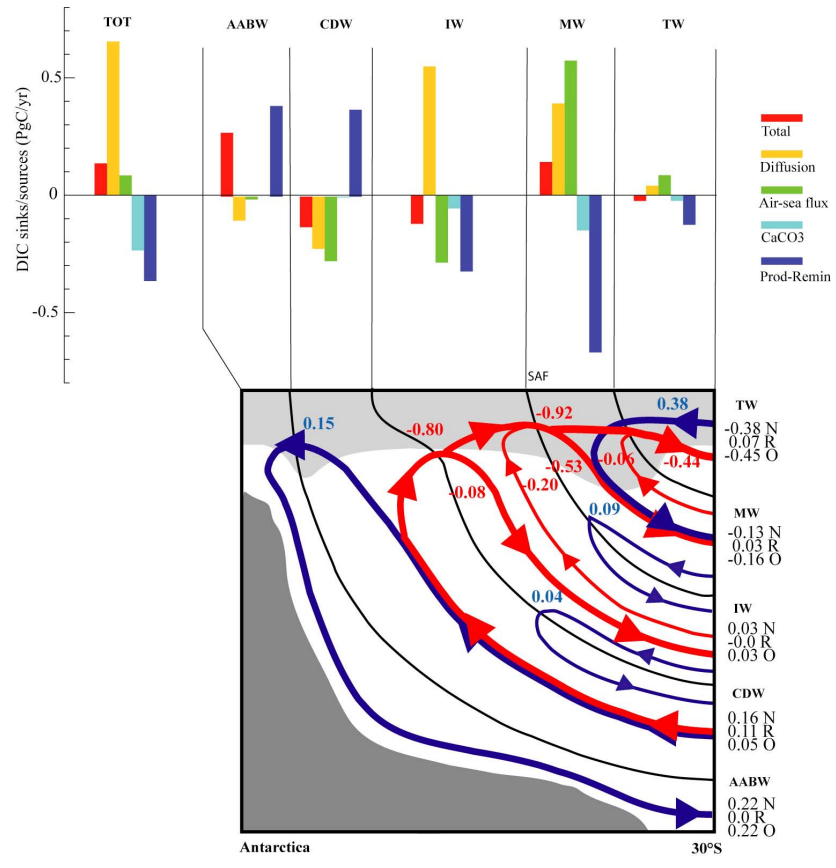

Fig. 7. Upper panel: budget $\left(\mathrm{PgC}^{-1}\right)$ per water masses of the sources/sinks of DIC Eq. (2). Lower panel: DIC sources/sinks associated with the different branches of the overturning circulation $\left(\mathrm{PgC}_{\mathrm{yr}}{ }^{-1}\right)$. The numbers along the vertical column correspond to: the gain/loss of DIC when the water mass leaves the Southern Ocean at $30^{\circ} \mathrm{S}(\mathrm{N})$, the gain/loss of DIC for the recirculation (R); and the gain/loss of DIC for the overturning. At the surface there are the air-sea $\mathrm{CO}_{2}$ fluxes $\left(\mathrm{PgC} \mathrm{yr}^{-1}\right)$ for each water mass computed considering the winter density while in parenthesis are the flux computed without considering the winter density. The light blue arrows indicate the fluxes toward the ocean while the magenta arrows indicate the fluxes toward the atmosphere.

DIC when it leaves the Southern Ocean. This is because the CDW that downwells gains DIC (via the process of remineralization).

Importantly, the largest contributions (in terms of absolute magnitude) that act along the pathways are sinks that are associated with upwelling. CDW experiences a substantial loss of DIC ( $\left.-0.80 \mathrm{Pg} \mathrm{Cyr}^{-1}\right)$ upon upwelling. It is worth noting that although the absolute value of this local sink is relatively large, the compensation between the sources and sinks over large scales results in their integrated contribution to the net export across $30^{\circ} \mathrm{S}$ being relatively small. As shown in Fig. 7, the absolute amplitude of the sources and sinks grouped by pathway are higher for pathways that pass through the bowl region (above the surface of the winter maximum mixed layer depth). This region includes most of the region of elevated solar incident radiation, and thereby effectively encompass the euphotic zone. However, given that we have thus far grouped all of the sources and sinks together, we do not know yet if the separate effects of biology, gas exchange, and other processes represent individually large or small modulations of the large transport values. 


\subsubsection{The DIC balance per water mass}

In order to identify the individual contributions to the integrated sources and sinks shown in Fig. 7, we now consider a new set of analyses focused on the different processes that control the DIC concentrations within the different water masses. To address how the redistribution of DIC by the thermohaline circulation (from the evaluation of $\Delta \Phi_{\gamma}$ above) compares with the total integrated effect of all sources and sinks of DIC, a quantitative balance of the sources and sinks per water mass can easily be evaluated by integrating the source and sink terms over the water mass volume. In other words, we consider now the terms $\Delta\left(-A_{\gamma}+\Sigma_{\gamma}+\Pi_{\gamma}\right)$ in Eq. (13). We wish to be clear here that we cannot associate sources and sinks with particular pathways or trajectories. This is because of the coarse-graining effect of integrating the Eulerian diagnostics (tendency terms) over entire water masses. We shall return to this point in the Discussion section.

Clearly the water mass volumes undergo large seasonal variations, e.g., large expanses of the surface layers south of the Antarctic Circumpolar Current fall in the AAIW class during the Austral Summer while in winter they are in the CDW class (see Iudicone et al., 2008a and Iudicone et al., $2008 \mathrm{c}$ for a discussion). Therefore, this analysis, as well as the analysis for the case of $\Phi_{\gamma}$, is intrinsically Lagrangian as it refers to following the water mass volume over the year and not to the DIC balance over a specific oceanic region. To ease the interpretation and the comparison with both the analysis of the air-sea $\mathrm{CO}_{2}$ fluxes presented in the companion study (Stendardo et al., 2011), the volume integral has been computed over the winter volume of the water mass (Fig. 7b). Since the seasonal variation of layer volume is only important near the surface, maintaining a fixed volume over the integration does not produce significant differences.

The integrated values for sources and losses are presented in Fig. 7 (upper panel). The integrals for the source and sink terms are conducted over two different domains, the first being the water masses over the entire Southern Ocean (Fig. 7) and the other for the euphotic zone only (Fig. 8). The euphotic zone is considered separately given its importance for biological production.

To reiterate, the net values of the sources and sinks are all significantly smaller than the transports (Fig. 3), while they can be large individually. On the whole the modeled Southern Ocean primary production $(\mathrm{P})$ is $10.2 \mathrm{Pg} \mathrm{Cyr}^{-1}$. Interestingly, this value is very close to the value of the upward branch of the upwelling of DIC in the overturning. Remineralization $(\mathrm{R})$ reconverts most of the organic matter into DIC, giving a net R-P balance of about $-0.4 \mathrm{Pg} \mathrm{C} \mathrm{yr}^{-1}$ (Fig. 7), i.e., only about $5 \%$ of the total production is exported out of the system. The formation of $\mathrm{CaCO}_{3}$ accounts

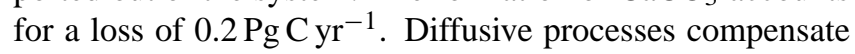
the biological net loss by producing a net DIC increase of $0.6 \mathrm{Pg} \mathrm{C} \mathrm{yr}^{-1}$, while air-sea fluxes have an almost null bud-

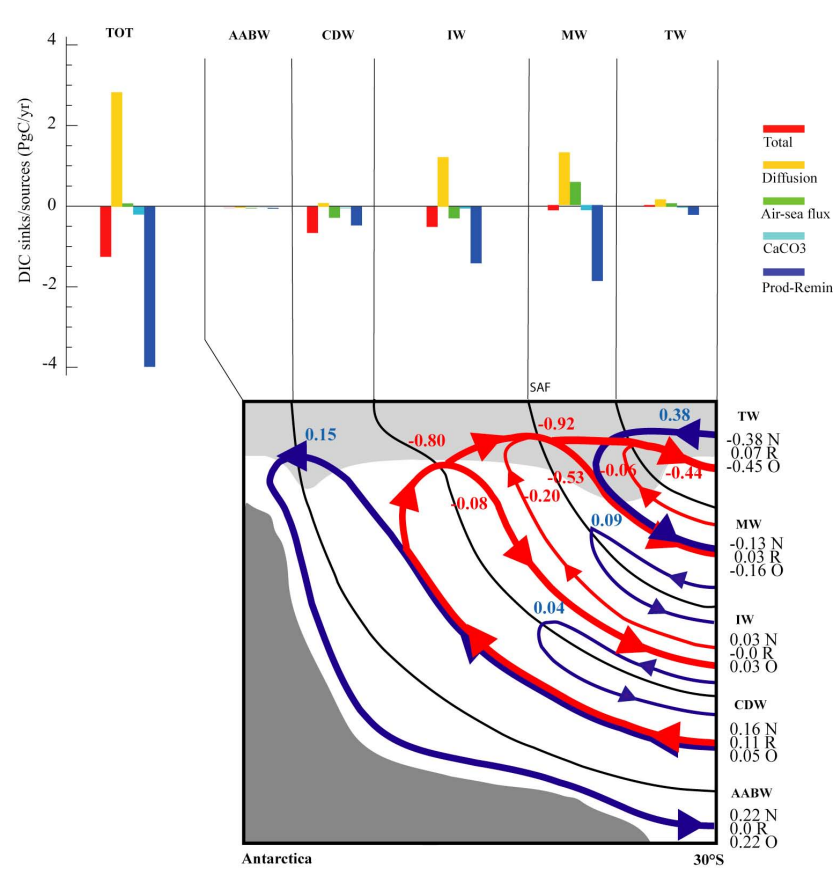

Fig. 8. Upper panel: the same budget as in Fig. 7 but for the upper $120 \mathrm{~m}$. Lower panel: DIC sources/sinks associated with the different branches of the overturning circulation $\left(\mathrm{PgC}^{-1}\right)$, i.e., the same as in Fig. 7. The numbers along the vertical column correspond to: the gain/loss of DIC when the water mass leaves the Southern Ocean at $30^{\circ} \mathrm{S}(\mathrm{N})$, the gain/loss of DIC for the recirculation (R); and the gain/loss of DIC for the overturning. At the surface there are the air-sea $\mathrm{CO}_{2}$ fluxes $\left(\mathrm{PgC} \mathrm{yr}^{-1}\right)$ for each water mass computed considering the winter density while in parenthesis are the flux computed without considering the winter density. The light blue arrows indicate the fluxes toward the ocean while the magenta arrows indicate the fluxes toward the atmosphere.

get $\left(0.1 \mathrm{Pg} \mathrm{C} \mathrm{yr}^{-1}\right)$. Clearly, diffusive processes significantly contribute to the smoothing-out of lateral DIC gradients at the main fronts.

The euphotic zone presents a net loss of more than 1.0 $\mathrm{PgC}_{\mathrm{yr}}{ }^{-1}$, and diffusion results in a flux in the opposite sense that largely compensates biology. Surface exchange of $\mathrm{CO}_{2}$ fluxes plays a secondary role. In this regard, only $\sim 40 \%$ of the model remineralization occurs at depth, with $\sim 60 \%$ occurring in the euphotic zone.

The partitioning of these values into the different water masses reveals several interesting points. First, as expected, the deep remineralization serves as a DIC source for deep water. For SAMW (Fig. 7), ingassing of $\mathrm{CO}_{2}$ contributes $0.6 \mathrm{PgC} \mathrm{yr}^{-1}$ while R-P serves as a sink of $-0.7 \mathrm{PgC}^{-1}$. This latter estimate is consistent with what has been described in observationally-based studies (e.g., McNeil and Tilbrook, 2009). The positive source contribution of mixing $\left(0.4 \mathrm{Pg} \mathrm{C} \mathrm{yr}^{-1}\right)$ is of the same order as gas exchange and biology, and contributes to the compensation of the sink due to biology. This contribution is significant, and as a result the total integrated sources and sinks is positive for SAMW. 
SAMW is clearly important for biological production, and the production rate within this water mass, lying north of the SAF, is $5.4 \mathrm{Pg} \mathrm{Cyr}^{-1}$ (this number is just over $50 \%$ of the total production integrated over the Southern Ocean in the model, with the second largest contribution coming from AAIW with 30\%). Given the importance of the SAMW as a formation region, it is of interest to consider the balance of the biology and mixing more specifically over the euphotic zone (Fig. 8). For SAMW in this region, the importance of diffusion (a source of $1.3 \mathrm{Pg} \mathrm{C} \mathrm{yr}^{-1}$ ) in compensating net effect of biology (a sink of $1.8 \mathrm{PgC} \mathrm{Cyr}^{-1}$ ) is even more pronounced. It is interesting to note that this large positive contribution from diffusion for SAMW within the euphotic zone implies a large negative contribution for SAMW elsewhere in the Southern Ocean (away from the outcrop).

For AAIW considered over the entire Southern Ocean, the net production sink is of the same order as the outgassing sink, and both of them are significantly smaller than the source associated with mixing. Considering AAIW integrated over the euphotic zone, the effect of biology (sink) is larger than the effect of mixing (source), leading to a net loss of order $0.5 \mathrm{PgC} \mathrm{yr}^{-1}$. For CDW integrated over the entire Southern Ocean, the main source is the remineralization and the sinks are outgassing and diffusion, with both of these losses being of the same order. In the euphotic zone, diffusion plays a much more minor role than it plays in either SAMW or AAIW. The largest sinks are due to outgassing and production.

In the companion paper to this study (Stendardo et al., in preparation), consideration is given to the seasonal cycle of the tendency terms for DIC for the surface layer. There it is emphasized that the various sources and sinks have distinct seasonal phasing by water mass, with diffusion increasing over the period of destratification and having maximum values in winter. Production is associated with the time of restratification, or reduced diffusion (see McNeil and Tilbrook (2009) for a quantitative estimate of the processes from in situ data). As expected, this phasing of physical and biological sources and sinks is distinct for the different water masses considered in this study. Although a detailed investigation of seasonal phasing of sources and sinks is beyond the scope of the present work, a more detailed mechanistic understanding of the interplay between these sources and sinks will require a more thorough investigation of the seasonal cycle.

\subsection{Characterising the carbon concentrations of the export}

While the main focus of this study has been on the processes determining the exchange of DIC by water mass between the Southern Ocean and the remainder of the global ocean, we wish to comment as well on the implications of the analysis on the concentrations of DIC at $30^{\circ} \mathrm{S}$. In Sect. 4 , an integrated view was given of the effects of different processes (water mass transformations, biology, mixing, and gas ex- change) in determining the tracer concentrations of water leaving the water volume under study Eqs. (13 and 14). Here we will apply these concepts to the export of DIC. By taking into account the transports of DIC across $30^{\circ} \mathrm{S}$ (Fig. 4), the net dianeutral transports (numbers on the right in Fig. 6), and the source/sink terms considered above, we can determine the relative amplitudes of the different processes in determining the DIC concentrations that are exported northward across $30^{\circ} \mathrm{S}$. The relative weights of the different processes are determined by dividing the DIC transports associated with each contribution by the northward transport of the water mass at $30^{\circ} \mathrm{S}$. It is important here to keep in mind that the northward transport across $30^{\circ} \mathrm{S}$ is distinct from the net export across $30^{\circ} \mathrm{S}$.

For the case of SAMW, from Eq. (13) it is found that the contribution of the source and sink terms is less than $1 \%$ of the total contribution from the other terms, i.e., from the convergence/divergence due to advective contributions, and it is thus negligible. Taking the ratio between the volume transport across each section and the northward volume transport in Eq. (14), we can evaluate the role of the DIC concentration of each water mass in contributing to setting the average DIC concentration of the northward-flowing SAMW. The DIC concentration of the southward flow of old SAMW contributes $74 \%$ while the densification of TW provides $21 \%$. The densification of deeper waters provides only $7 \%$. The sum here does not total $100 \%$ due to roundoff errors. For the case of AAIW, sources and sinks are similarly found to be negligible. The southward flow of older AAIW provides $90 \%$, the lightening of CDW provides $23 \%$, and the advective transport between AAIW and SAMW densities is a negative contribution of $-13 \%$.

Significantly, this implies that a mixing ratio interpretation seems appropriate for the dominant processes controlling the average DIC concentrations of water exported northward across $30^{\circ} \mathrm{S}$. Therefore, for the coarse-grained representation of the circulation implied by the division of the ocean into the discrete layers described in Table 1, the DIC concentrations of exported waters do not represent local sources and sinks over the Southern Ocean, but rather non-local (regions north of $30^{\circ} \mathrm{S}$ ) sources and sinks that set the concentration of the source waters elsewhere. In particular, the Southern Ocean acts as a smoother of the sub-surface vertical gradients created by the biological pump and by other processes in other regions of the oceans. For the case of total northward transport of SAMW, the concentrations of exported waters are largely reflecting the mixing ratio of the relatively DIC-depleted TW and the denser waters, with local biological processes, gas exchange, and mixing offering only small modifications. 


\section{Discussion}

The main goal of this study was to characterize the Southern Ocean controls on the exchange of carbon with the rest of the ocean across $30^{\circ} \mathrm{S}$. In order to achieve this goal, we developed a new water mass-based framework that makes combined use of both Lagrangian and Eulerian diagnostic tools. These tools allowed us to compare the relative roles of water mass transformations, biology, gas exchange, and mixing on the transports of DIC referenced to $30^{\circ} \mathrm{S}$. This new framework and these new methods allowed us to infer the relative impacts of these processes on tracer concentrations.

\subsection{The new approach}

To study the interplay between the cyclo-stationary overturning circulation of the Southern Ocean and the natural carbon cycle, we extended a set of diagnostic tools grounded in the methods developed and applied by Iudicone et al. (2008a, b, c) for characterising the role of Southern Ocean water mass transformations in global ocean circulation. This choice was motivated by our larger goal of understanding the role of the Southern Ocean in the global response to climate change.

The diagnostic tools developed and applied here exploit both Eulerian and Lagrangian approaches. The strength of the Eulerian method is in facilitating the comparisons of the roles of diapycnal transports of volume/mass with the effect of internal sources and sinks on DIC transports. It gives a transport-weighted average of the contribution of each process in setting the mean tracer value along the boundary, as presented in Sect. 5. It is nevertheless important to exercise caution in interpreting the method, which gives global budgets over the water mass, since it does not intend to account for what specifically sets the fine scale tracer concentrations (in this case, DIC) at the boundary of the domain.

The principal strength of the Lagrangian approach with DIC is that it provides for a quantitative description of the large-scale three-dimensional pathways associated with the overturning circulation, and its role in the DIC redistribution across the reference latitude at $30^{\circ} \mathrm{S}$. It also provides an integrated view of sources and sinks across the various pathways. As this approach follows the streamlines and does not explicitly take into account diffusion, it is thus complementary to other approaches that have been developed for understanding ventilation pathways and exchanges in the ocean interior, such as that of Palter et al. (2010) or Khatiwala et al. (2009).

\subsection{The main results}

Marinov et al. (2006) have argued that the Polar Front provides a Biogeochemical Divide that separates the Southern Ocean into two important regions, which are distinguished by their controls on air-sea $\mathrm{CO}_{2}$ fluxes and biological production. Here we have shown that these surface delimited regions are tightly connected with large-scale overturning and water mass transformation processes. As for the spatial dimension, our analysis confirmed a functional divide in the Southern Ocean between a region of carbon uptake north of the SAF, in the region of formation of SAMW, and an outgassing region along and south of the SAF, including the regions of AAIW formation. Although the results should be considered to be accurate and quantitatively robust for the model configuration used here, it remains to be tested whether the results are particularly model- or resolutionspecific. Some caveats are listed below.

First, the Lagrangian analysis showed that two-thirds of the net export of DIC in SAMW is provided by densification of TW. The details of this result are of course model dependent and it is difficult to validate the result against observationally-based estimates of the TW contributions to SAMW formation since they vary significantly (e.g., Talley et al, 2003; Sloyan and Rintoul 2001). As mentioned in the appendix, the evaluation of the model output with CFCs revealed a very good agreement with inventories in the Atlantic and Pacific sectors while the Indian sector ventilation is overestimated by a factor between 1.5 and 2 . Interestingly, McNeil et al. (2001) used salinity and CFC-11 mass balance to determine the contributions of TW and Antarctic Surface Water (in the AAIW class) to SAMW formation. They found that the TW contributes $75 \pm 6 \%$, in accord with our results. This is thus in agreement with the emerging view in the physical oceanographic community of the interactions between the subtropical gyres and the polar regions that occurs in proximity of the Southern Ocean fronts (see Figs. 1 and 2a). The AAIW export presents partially compensating pathways, resulting in a small net export. These results should serve to motivate a rethinking of the predominant paradigm of Southern Ocean overturning that is used in the biogeochemical community (Fig. 2b), which suggests that surface lightening of recently upwelled CDW has a dominant role in the formation of both AAIW and SAMW.

The companion Eulerian analysis revealed the importance of the surface buoyancy fluxes in sustaining the export of DIC from the upwelling CDW toward SAMW and AAIW density classes. The effect of these fluxes is to a significant extent compensated by vertical and lateral mixing, the latter partly occurring at depth as the result of non-linear processes (i.e., cabbeling). One of the reasons for the common (while implicit) use of a water mass framework resides in the assumption that the interior circulation of the oceans is almost inviscid and that no significant exchanges occur across isopycnals. Our results show that over the Southern Ocean, although the surface layer is the most important location for both water mass transformations and the other processes that modulate DIC export, internal processes do also contribute. This is consistent with previous studies that emphasized the importance of internal processes such as penetrative solar radiation (Iudicone et al., 2008a), small scale turbulence (Naveira Garabato et al., 2007) and cabbeling/thermobaricity (e.g., Iudicone et al., 2008a; Zika et al., 
2009) in transforming water mass after the formation at the surface. We can suppose that they could be even more relevant for tracers that present important discontinuities at the water mass boundaries, as is the case for nutrients or transient tracers such as anthropogenic $\mathrm{CO}_{2}$.

The Lagrangian quantitative analysis of the sources and sinks along each pathway of the overturning and of the recirculation revealed that the latter, while associated with a much larger DIC transport, have in general a reduced net change. The reason is that the recirculation occurs mostly in the interior while only the pathways passing close to the surface are significantly impacted, as expected. However the main results is that these changes are very small, when compared to the transports. Moreover, the largest change, the sink along the branches of the CDW upwelling $\left(0.92 \mathrm{PgC}^{-1}\right.$, i.e., a loss of $10 \%$ of the DIC content), is approximately twice as large as the local outgassing. These sinks are partly compensated by the net source experienced by the downwelling (shallow overturning) that contributes to the formation of SAMW and AAIW. The balance of the different processes acting on a single water mass showed that diffusion is comparable to the net biological effects. Additionally, biological production is significantly compensated by remineralization. Gas exchange, while obviously important for transient climate adjustment, is generally smaller than the above terms. An evaluation of the mixing ratios for the DIC values in the northward flows confirmed the importance of recirculation in the subtropical gyres and how the convergence of waters with different DIC values overwhelms the effect of sources and sinks.

We have seen that globally, integrated over water masses, the contribution of biology is smaller than diapycnal transports within the framework of characterizing the export across $30^{\circ} \mathrm{S}$. In particular, the relatively low DIC concentrations in SAMW and AAIW, which contribute significantly in setting the vertical DIC profile of the global oceans, is to first order set by the influence of TW in water mass formation. Local processes such as gas exchange or biology have lesser roles. This does not imply that biology is not important in determining the vertical distribution of carbon in the global ocean or in contributing to gas exchange. In fact, the relatively low DIC concentrations in TW are set, at least in part, by biology. However this occurs north of the area of interest here. Within the Southern Ocean, while the amplitude of primary production near the surface is significant, much of the effect of biology is compensated by (largely vertical) diffusion near the surface. For the model runs and density classes considered here, much of this occurs within the same water mass. Likewise lateral diffusivity can be important at depth. In summary, biology is important, but the imprint of the overturning circulation is stronger.

One of our objectives was also to identify the role of diffusion in the large-scale controls of DIC over the Southern ocean. Consistent with what was found by (Le Quéré et al., 2003) and (Verdy et al., 2007) for the case of interannual variability, we have seen here for the cyclostationary circulation that diffusion/entrainment is a first-order process for the control of DIC. Nevertheless, while processes acting on the DIC are in near-balance when considered as an annual average, the system can not and should not be thought of as being in steady-state balance over the seasonal cycle. Therefore a more careful evaluation of processes as they operate on seasonal timescales is required to understand the processes that set the pre-formed concentration of DIC at the moment of detrainment/subduction. In fact, the analysis considered here has been extended to consider seasonal variations in a companion study (Stendardo et al., 2011) There it is shown that in late winter DIC concentrations reflect a balance between vertical diffusion, vertical and lateral advection, and air-sea $\mathrm{CO}_{2}$ fluxes. These processes and their amplitudes in late winter are also impacted by the redistributions of DIC achieved by biology during spring and summer. This analysis will serve as a basis to extend the previous theoretical work of Ito et al. (2004) in a future study.

Importantly, the results presented here provide a dynamical framework for interpreting the $\Delta C_{\text {gasex }}$ tracer presented in Fig. 1 of (Mikaloff-Fletcher et al., 2007) as a diagnostic of the pre-anthropogenic oceanic carbon cycle. This diagnostic of ocean interior DIC in the AAIW density class in the Southern Ocean revealed that the interior tracer signature is consistent with $\mathrm{CO}_{2}$ outgassing when the water mass was last at the surface, while for the SAMW density class it was shown to be suggestive of an ingassing signature. The latter point is important, as it offers independent evidence that SAMW formation is dominated by the densification of TW. It also implies that AAIW is not merely a denser version of SAMW, but rather that it has a distinct and independent formation process. These results are consistent with previous studies (e.g., Iudicone et al., 2007).

For the case of the AAIW exported across $30^{\circ} \mathrm{S}$, this outgassing signature from when the water was last at the surface can be interpreted to reflect the combined effect of several processes. These include the northward Ekman transport of recently upwelled CDW, lateral mixing processes, and importantly, to the occurrence a partial upwelling of CDW into this density class, in the form of entrainment at the base of the mixed layer. This consistency between one of our main results and an independent method using quasi-conservate tracers of the carbon cycle that are anchored in data is important. It indicates that despite some of the known caveats of modeling ocean biogeochemistry (imperfect representation of mixing, biology, gas exchange, etc.), the main results of our work are consistent with inferences from independent methods that are more closely constrained by observations. Of course the results presented here indicate also that a more detailed process-understanding of the $\Delta C_{\text {gasex }}$ tracer should consider the relative contributions of diffusion, biology, advection, gas exchange, etc. to setting the pre-formed $\Delta C_{\text {gasex }}$ values associated with the formation process. Although providing a detailed mechanistic account of the processes that 
set $\Delta C_{\text {gasex }}$ are beyond the scope of this paper (it would require a detailed analysis of the seasonal cycle), the methods presented here could be helpful both for understanding processes controlling pre-formed carbon and nutrients, as well as the application to reducing uncertainty in detection.

\subsection{Caveats and implications}

The results presented here derive from the analysis of one single model solution. However, they should by no means be considered to be the the final word as some of the details may reflect particularities of the model configuration considered here. As far as methods are concerned, the work here should be interpreted as being a proof of concept that illustrates the power of a combined Eulerian/Lagrangian approach to understand the large-scale controls on the ocean carbon cycle. Here the application was for the mean state; in other words, for the processes controlling the exchange of carbon across $30^{\circ} \mathrm{S}$ for a climatologically-varying ocean state. Achieving the longer term goal of developing a tool for understanding the more general case of time-varying circulation for the case of transient tracers, a number of steps would be appropriate.

One direction of work will involve the improvement of models, and the correction of understood biases. One important bias involves the challenges of modeling ocean biogeochemistry on global scales. We have seen that for both DIC and alkalinity, the model reveals differences in the largescale vertical gradients between the upper ocean and the deep ocean. Clearly the modeled gradients in DIC are larger in the model than in the GLODAP data product, but this should be expected to only impact in a relatively minor way the way in which the overturning transports project onto DIC export. Certainly the details of the modification (categorized by water mass) of the effects of biology, gas exchange, buoyancy fluxes, mixing will be model dependent, but the relatively modest imprint of these processes to the overall export is expected to be robust, even if the uncertainty of the contributions of individual processes are difficult to quantify.

Other important biases are associated with the global ocean circulation. It is widely known that there are discrepancies between model-derived and data-derived inferences of the large-scale overturning of the Southern Ocean (especially in terms of bottom waters formation; e.g., Sloyan and Rintoul, 2001; Talley 2003, Lumpkin and Speer, 2007), and until this is resolved the results here may be deemed to be modeldependent. Nevertheless, and importantly, the ocean overturning state used here (described in Iudicone et al., 2008b) is certainly within the outliers of the range of ocean model overturning states evaluated in previous studies (e.g., Downes et al., submitted). Another bias is associated with the fact that the method is based on a binning procedure which is not free of errors as it is a finite-size approximation of a differential equation (Eq. (8); the errors are discussed in Iudicone et al., 2008b). Finally, the diagnostics presented here are calculated off-line using bi-weekly means of the physical state variables of the circulation model. Thus some of the non-linearities in both ocean circulation and ocean biogeochemistry are obscured by this averaging process (see Appendix in Iudicone et al. 2008b). For future work it will be desirable to evaluate time sampling of the model outputs that captures the critical timescales of the relevant processes. Better yet, it may be appropraite to include the water mass diagnostics as an on-line diagnostic.

The Lagrangian tool ARIANE (http://stockage.univ-brest. $\mathrm{fr} / \sim$ grima/Ariane/ariane.html) we have used here has been previously applied to a wide range of topics involving tracing the oceanic circulation, and considering the fate of tracers such as salinity. It is part of a suite of codes developed on the same analytical approach for quantitative transport estimates (http://doos.misu.su.se/tracmass/ tracmassproject/index.html). The method has been developed to trace the streamlines along which tracers are transported in GCMs (including bolus transports) and, therefore, first, it follows the mean pathways and does not consider the effect of mixing other then its effect on the mean flow. For instance, in the mixed layer the trajectories will follow the mean flow and they are not mixed by the effect of local turbulence. Further, it does not follow a specific tracer path but takes account the advective component of the tracer transport. Since our focus here was the interplay between the oceanic circulation and processes and the carbon cycle, our principal questions of interest were: how is DIC redistributed by oceanic overturning? How DIC changes along the streamlines of the overturning? Keeping these questions in mind, it is thus clear that the Lagrangian approach is thus perfectly suitable for the task.

The use of bi-weekly outputs can also impact the Lagrangian estimates of the transports, which are computed offline. Using our same code, in specific studies on the sensitivity of Lagrangian transport estimates to time sampling Iudicone et al. (2002) and Valdivieso Da Costa and Blanke (2004) found that in non-eddying models the time scale to be resolved is that of the surface forcing. More specifically, Valdivieso Da Costa and Blanke (2004) found that, for a time sampling shorter than the time scale of the forcing, the errors on the transport estimates are in general $<5 \%$ and in most cases $<1 \%$. Since their model configuration is very close to our physical model configuration, we can safely affirm that Lagrangian estimates are correct within a few per cent. Finally, due to the smoothing inherent in the forcing fields, the effect of inertial oscillations is not present in the physical state variables that drives the PISCES biogeochemistry model.

Finally, in future investigations involving a wide range of depth horizons, it will be appropriate to perform analyses using neutral densities, despite the fact that this will inevitably complicate some of the complications involved. Regarding the latter point, care has to be taken with regard to the details of the computation of the water mass transformations, which implies the empirical evaluation of the ratio of the gradients 
of the neutral density and locally referenced density. This is a rather noisy quantity, as is discussed in the Appendix of Iudicone et al. (2008b).

The combined Eulerian/Lagrangian tools developed here are intended to be general diagnostics of ocean circulation. The extension of the method presented here to fully timevarying circulation states will be an important priority for extending the present work, as well as to the application of the method to other tracers in the ocean. It should also provide a means to better understand their dynamical coupling with the ocean physics. For the case of anthropogenic carbon, this should help to identify the dynamical controls on the density surfaces where anthropogenic accumulates in the ocean interior. The same method can be easily extended to time fully varying cases, from local phenomena such as coastal systems, investigated at high resolution, to large scale systems. In our opinion, it will be particularily useful also to quantitatively evaluate the results of numerical sensitivity experiments (e.g., where a set of runs is done changing, each time, the model parameters). In too many cases the differences are evaluated via qualitative comparisons. With the method presented here the response of each process could be instead analyzed separately. Finally, these approaches could be of use for deriving simplified, dynamical box model-like schemes from complex GCM computations.

It is important to keep in mind that the ocean dynamics (e.g., the residual circulation resulting from the superposition of Ekman and eddy (bolus) circulations) is contained in the advective component of the tracer equation. (A brief discussion on the analysis of the terms on the left hand side of the density equation is presented in Iudicone et al., 2008a). A more comprehensive evaluation of the relationship between the residual mean circulation and the transformations considered here is beyond the scope of this work, but should be an important question to consider in future investigations as, for instance, eddy-permitting forced ocean model simulations indicate that an important type of process for transporting light TW into SAMW formation regions may involve eddy-shedding from boundary currents (e.g., Hallberg and Gnanadesikan, 2006). This could be relevant for the understanding of the dynamics of Southern Ocean biogeochemical cycling, building upon theoretical studies such as that presented in Ito et al. (2004).

Finally, as we saw in the Results section, it is not yet possible to quantitatively associate sources and sinks along Lagrangian trajectory pathways as the analysis of the source and sink terms are presently considered as an integral over a water mass. It will be important to develop this capacity at a later stage, and this could be accomplished by building on the volume-following quantitative approach here used together with the preliminary qualitative steps in this direction that were explored in the works of Radenac et al. (2005) and Verdy et al. (2007).

\section{Conclusions}

This study was organized around the following question: What are the processes that control the exchange of DIC across $30^{\circ} \mathrm{S}$ in the ocean interior? We have found that the dominant water masses for the net export of DIC across $30^{\circ} \mathrm{S}$ are SAMW and AABW, with AAIW playing a significantly smaller role. This export is compensated by an southern inflow of TW and CDW across $30^{\circ} \mathrm{S}$. An important new result is that the dominant process sustaining the export of DIC in the SAMW density class is not the lightening of CDW (this supplies only one-third of the SAMW export of DIC), but rather the densification of TW (this supplies two-thirds of the SAMW export of DIC). Additionally, only a small fraction of CDW that is consumed in the Southern Ocean is subsequently exported to the north across $30^{\circ} \mathrm{S}$ in the AAIW density class, while $45 \%$ of this DIC of CDW origin is exported to the north in the AABW density class.

These important differences in SAMW and AAIW export of DIC from the Southern Ocean have been shown to be consequences of differences in their physical formation processes. These differences in formation processes are fully consistent with the large-scale circulation patterns that have been inferred from observations (Talley et al., 2003), and thus the model results here are deemed to be robust, despite potential caveats related to non-eddying model resolution and modest biases (less than $10 \%$ relative to the mean) in interior DIC concentrations.

This study also implies that local biological processes over the Southern Ocean play a secondary role in prescribing the DIC export across $30^{\circ} \mathrm{S}$ by density class. Similarly, air-sea $\mathrm{CO}_{2}$ exchange over the Southern Ocean has only a secondary role in determining DIC exchange across $30^{\circ} \mathrm{S}$. We found that biology, gas exchange, and mixing processes are often compensating for each other, with the absolute values of each process typically being substantially smaller than the amplitude of the water mass transformations. A more specific focus on the seasonally evolving balance between biology, gas exchange, and mixing processes that set preformed DIC concentrations in late winter at the time of detrainment/subduction is left as a subject for future investigation.

The paradigm emerging from this analysis is that local biological and gas exchange processes within the modeled Southern Ocean play secondary roles to physical transformations in prescribing the vertical gradient of DIC over much of the region to the north of $30^{\circ} \mathrm{S}$. We by no means wish to imply that gas exchange and biology are not important processes for understanding transient climate responses. Rather, we wish to emphasize that the tools developed and presented here are perfectly general and will be appropriate for evaluating the roles of gas exchange and biology in interpreting transient climate responses. 


\section{Appendix A}

\section{Model description}

The biogeochemical model PISCES is based on HAMOCC5 (Aumont et al., 2003) and simulates the biogeochemical cycle of oxygen, carbon and of the main nutrients that control marine phytoplankton growth: nitrate and ammonium, phosphate, silicate and iron (Aumont et al., 2003, Aumont and Bopp, 2006). The Redfield ratio is constant and phytoplankton growth is limited by the external availability of nutrients. The cycle of carbon and nitrogen are decoupled in the model to a certain degree by nitrogen fixation and denitrification (Gehlen et al., 2006). PISCES has twenty-four compartments. There are five limiting nutrients for phytoplankton growth (nitrate, ammonium, phosphate, silicate and iron). Four living compartments: two phytoplankton size-classes corresponding to nanophytoplankton and diatoms and two zooplankton size classes which are microzooplankton and mesozooplankton. The phytoplankton is represented in total biomass, iron, chlorophyll and silicon contents. The zooplankton is modeled only in total biomass. There are three non-living compartments: semi-labile dissolved organic matter, small and big sinking particles. The iron, silicon and calcite pools of particles are explicitly modeled. In addition to the ecosystem model, PISCES also simulates dissolved inorganic carbon, total alkalinity and dissolved oxygen.

In the ice-ocean coupled model ORCA2-LIM, LIM is the sea ice model (Fichefet and Maqueda (1997), Timmermann et al., 2005). It is a fully dynamical-thermodynamical sea ice model. The ocean model is the OPA model (Madec et al., 1998; Delecluse and Madec, 1999) in its global configuration ORCA2. The horizontal mesh is based on a $2^{\circ}$ by $2^{\circ}$ Mercator grid. There are 31 levels in the vertical, with the highest resolution $(10 \mathrm{~m})$ in the upper $150 \mathrm{~m}$. The upper boundary uses a free surface formulation (Roullet and Madec, 2000). Lateral mixing is evaluated along isoneutral surfaces. The model is supplemented with the (Gent and McWilliams, 1990) parameterization. The lateral mixing coefficient depends on the baroclinic instability growth rate(Treguier et al., 1997). The vertical mixing scheme uses a turbulent closure (Blanke and Delecluse, 1993), and there is a diffusive bottom boundary layer parameterization (Beckmann and Doscher, 1997). The model background vertical diffusivity increases from the surface to the bottom in order to mimic the effects of decreased stratification and increased small-scale turbulence near the bottom (Values ranges from $0.12 \times 10^{-4} \mathrm{~m}^{2} \mathrm{~s}^{-1}$ in the first $1000 \mathrm{~m}$ to $1.2 \times 10^{-4} \mathrm{~m}^{2} \mathrm{~s}^{-1}$ at depth). Convection is emulated via an enhanced vertical diffusivity. At surface the ocean model is forced by computing fluxes of heat and freshwater (evaporation) by means of bulk formulae and using monthly climatologies of atmospheric forcings. A penetrative shortwave solar radiation formulation is used. A restoring to climatological surface salinities was also added. Climatological
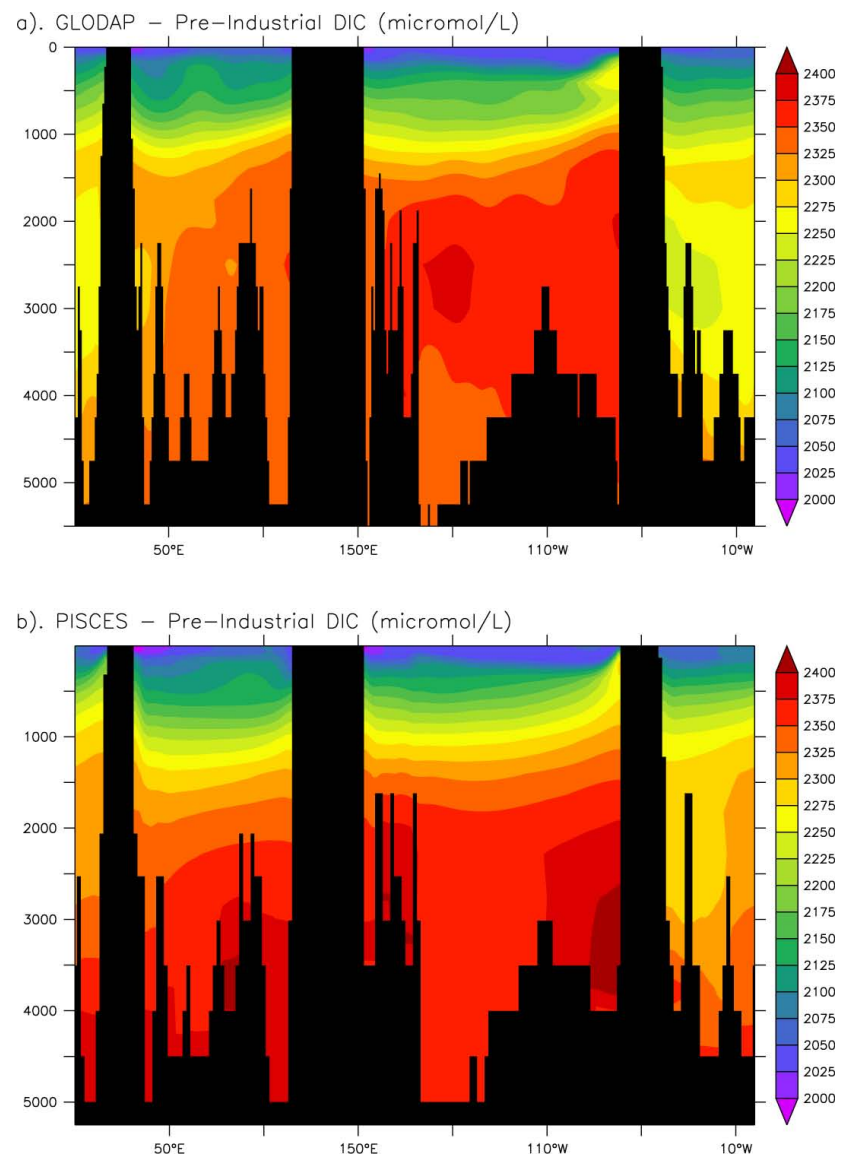

Fig. A1. Upper panel: GLODAP DIC section at $30^{\circ} \mathrm{S}$. Lower panel: PISCES DIC section at $30^{\circ} \mathrm{S}$.

ERS1/2 scatterometer monthly mean wind stresses were used for the tropics while the NCEP/NCAR climatology was used poleward of $50^{\circ} \mathrm{N}$ and $50^{\circ} \mathrm{S}$. In low and intermediate resolution OGCM, time variability is in most case limited to forcing variability and thus for the analysis we used a model time sampling of 14.6 days to resolve the main time scale of the forcing. Consistently, we used a same model time sampling in the biogeochemical model.

The configuration we used for this study is the same of the published studies of Iudicone et al. (2008a, b, c), and the published version of the PISCES model (Aumont and Bopp, 2006) without no changes. The circulation model itself has been extensively evaluated with a wide number of tracers (CFCs, C14, $\mathrm{He}_{3}$, hydrography, mixed layer depth, sea surface height), and it represents the best of the set of runs presented in Dutay et al. (2009). The main limits of the simulations are the relatively weak bottom cell (AABW) and an overestimation of the SAMW formation in the Indian sector of the Southern Ocean.

The biogeochemical scheme PISCES has also been extensively evaluated (see Auxiliary Materials of Aumont and Bopp, 2006). Nevertheless, we wish to emphasize that this 


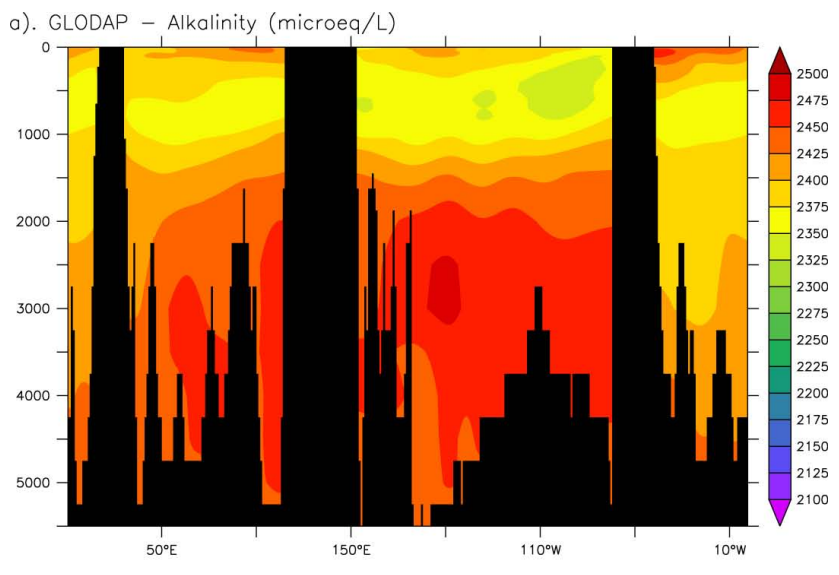

b). PISCES - Alkalinity (microeq/L)

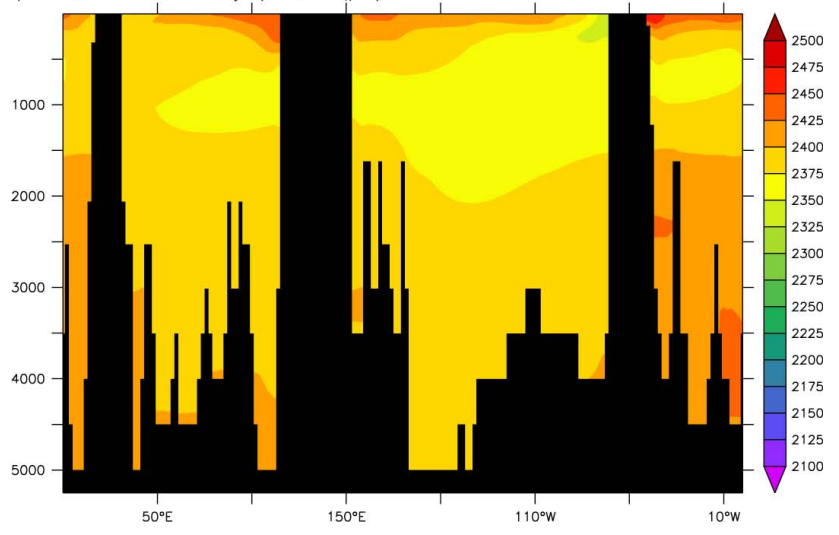

Fig. A2. Upper panel: GLODAP alkalinity section at $30^{\circ} \mathrm{S}$. Lower panel: PISCES alkalinity section at $30^{\circ} \mathrm{S}$.

state-of-the-art model has a number of biases that are characteristic of all global ocean models, especially those that are run up a few thousand of years to equilibrium and those that include alkalinity as a prognostic tracer (alkalinity is prognostically computed based on a variety of processes, carbonate production and dissolution, organic matter production and remineralization (see Eq. (42) of Aumont and Bopp (2006) - Auxiliary Material for a complete equation).

Figures A1 and A2 shows DIC and ALK sections at $30^{\circ} \mathrm{S}$, corresponding to WOCE cruise tracks and therefore are not compromised by significant mapping errors. While improving the match with DIC distributions there is a clear underestimation of alkalinity at depth (by as much as $75 \mathrm{~mol} \mathrm{~L}^{-1}$ ) in the Pacific and Indian basins. Such deficiency in Alkalinity is due to the fact that there is too little carbonate production and export in the version of PISCES used here (e.g., Aumont and Bopp, 2006). However, the important surface-to-surface gradients in this version of PISCES capture the important gradients down to $1000 \mathrm{~m}$ depth seen in the observations, thus minimizing a possible bias of of alkalinity in the sea surface $p \mathrm{CO}_{2}$ through the effect of upwelling.
Acknowledgements. This work is dedicated to the memory of Dr. Volfango Rupolo, a mentor in both oceanography and life for DI, and above all a dear friend for 20 years. Volfango died 5 April 2010, at the age of 46 years and 1 day.

We gratefully acknowledge the support by Vincenzo Saggiomo. We would like to thank Bruno Blanke for providing the Lagrangian ARIANE code (http://stockage.univ-brest.fr/ grima/Ariane/) and for the support for its optimal use. We would like to thank Sarah E. Mikaloff Fletcher, Stephen Griffies and Jorge L. Sarmiento for helpful discussions and suggestions. Discussion with B. Linne' are also kindly acknowledged. We would like to thank the three anonymous referees for providing us with constructive comments and suggestions.

The work was partly done in the framework of PEA-CANOPO and VECTOR Projects.

The contribution of KBR was partially supported by the Carbon Mitigation Initiative (CMI) project at Princeton University, sponsored by BP and the Ford Motor Company, and by NASA award NNX09AI13G. Additionally, the contribution of KBR was also partially supported through awards NA17RJ2612 and NA08OAR4320752, which includes support through the NOAA Office of Climate Observations (OCO). The statements, findings, conclusions, and recommendations are those of the authors and do not necessarily reflect the views of the National Oceanic and Atmospheric Administration or the US Department of Commerce.

Edited by: G. Herndl

\section{References}

Anderson, R. F., Ali, S., Bradtmiller, L. I., Nielsen, S. H. H., Fleisher, M. Q., Anderson, B. E., and Burckle, L. H.: Winddriven upwelling in the Southern Ocean and the deglacial rise in atmospheric $\mathrm{CO}_{2}$, Science, 323, 1443-1448, 2009.

Aumont, O. and Bopp, L.: Globalizing results from ocean in situ iron fertilization studies, Global Biogeochem. Cy., 20, GB2017, doi:10.1029/2005GB002591, 2006.

Aumont, O., Maier-Reimer, E., Blain, S., and Monfray, P.: An ecosystem model of the global ocean including $\mathrm{Fe}$, Si, P colimitations, Global Biogeochem. Cy., 17, 1060, doi:10.1029/2001GB001745, 2003.

Beckmann, A. and Doscher, R.: A method for improved representation of dense water spreading over topography in geopotentialcoordinate models, J. Phys. Oceanogr., 27, 581-591, 1997.

Blanke, B. and Delecluse, P.: Variability of the tropical Atlanticocean simulated by a general-circulation model with 2 different mixed-layer physics, J. Phys. Oceanogr., 23, 1363-1388, 1993.

Blanke, B. and Raynaud, S.: Kinematics of the Pacific equatorial undercurrent: An Eulerian and Lagrangian approach from GCM results, J. Phys. Oceanogr., 27, 1038-1053, 1997.

Delecluse, P. and Madec, G.: Ocean modelling and the role of the ocean in the climate system, in: Modeling the Earth's climate and it's variability, edited by: Holland, W. R. and Joussaume, S., and David, F., 67, Les Houches summer school session, 237-313, 1999.

Döös, K.: Inter-ocean exchange of water masses, J. Geophys. Res., 100, 13499-13514, 1995. 
Döös, K., Nycander, J., and Coward, A.: Lagrangian decomposition of the Deacon Cell, J. Geophys. Res., 113, C07028, doi:10.1029/2007JC004351, 2008.

d'Orgeville, M Sijp, W., England, M., and Meissner, K.: On the control of glacial-interglacial atmospheric $\mathrm{CO}_{2}$ variations by the Southern Hemisphere westerlies, Geophys. Res. Lett., 37, L21703, doi:10.1029/2010GL045261, 2010.

Fichefet, T. and Maqueda, M. A. M.: Sensitivity of a global sea ice model to the treatment of ice thermodynamics and dynamics, J. Geophys. Res., 102, 12609-12646, 1997.

Gehlen, M., Bopp, L., Ernprin, N., Aumont, O., Heinze, C., and Raguencau, O.: Reconciling surface ocean productivity, export fluxes and sediment composition in a global biogeochemical ocean model, Biogeosciences, 3, 521-537, 2006.

Gent, P. R. and McWilliams, J. C.: Isopycnal mixing in ocean circulation models, J. Phys. Oceanogr., 20, 150-155, 1990.

Greatbatch, R. J. and Zhai, X.: The Generalized heat function, Geophys. Res. Lett., 34, L21601, doi:10.1029/2007GL031427, 2007.

Hallberg, R. and Gnanadesikan, A.: The role of eddies in determining the structure and response of the wind-driven Southern Hemisphere overturning: Results from the Modeling Eddies in the Southern Ocean (MESO) project, J. Phys. Oceanogr., 36, 2232-2252, 2006.

Ito, T., Marshall, J., and Follows, M.: What controls the uptake of transient tracers in the Southern Ocean, Global Biogeochem. Cy., 18, GB2021, doi:10.1029/2003GB002103, 2004.

Iudicone, D., Lacorata, G., Rupolo, V., Santoleri, R., and Vulpiani, A.: Sensitivity of numerical tracer trajectories to uncertainties in OGCM velocity fields, Ocean Modell., 4, 313-325, 2002.

Iudicone, D., Rodgers, K., Schopp, R., and Madec, G.: An exchange window for the injection of Antarctic Intermediate Water into the South Pacific, J. Phys. Oceanogr., 37, 31-49, 2007.

Iudicone, D., Madec, G., Blanke, B., and Speich, S.: The role of Southern Ocean surface forcings and mixing in the global conveyor, J. Phys. Oceanogr., 38, 1377-1400, 2008a.

Iudicone, D., Madec, G., and McDougall, T. J.: Water-mass transformations in a neutral density framework and the key role of light penetration, J. Phys. Oceanogr., 38, 1357-1376, 2008b.

Iudicone, D., Speich, S., Madec, G., and Blanke, B.: The global conveyor belt from a Southern Ocean perspective, J. Phys. Oceanogr., 38, 1401-1425, 2008c.

Jackett, D. R. and McDougall, T. J.: A neutral density variable for the worlds oceans, J. Phys. Oceanogr., 27, 237-263, 1997.

Johnston, T. and Rudnick, D.: Observations of the Transition Layer, J. Phys. Oceanogr., 39, 780-797, 2009.

Khatiwala, S., Primeau, F., and Hall, T.: Reconstruction of the history of anthropogenic $\mathrm{CO}_{2}$ concentrations in the ocean, Nature, 462, 346-349, 2009.

Le Quéré, C., Aumont, O., Monfray, P., and Orr, J.: Propagation of climatic events on ocean stratification, marine biology, and $\mathrm{CO}_{2}$ : Case studies over the 1979-1999 period, J. Geophys. Res., 108, 3375, doi:10.1029/2001JC000920, 2003.

Le Quéré, C., Rödenbeck, C., Buitenhuis, E. T., Conway, T. J., Langenfelds, R., Gomez, A., Labuschagne, C., Ramonet, M., Nakazawa, T., Metzl, N., and Gillett, N., and Heimann, M.: Saturation of the Southern Ocean $\mathrm{CO}_{2}$ sink due to recent climate change, Science, 316, 1735-1738, 2007.

Lumpkin, R. and Speer, K.: Global ocean meridional overturning, J. Phys. Oceanogr., 37, 2550-2562, 2007.
Madec, G., Delecluse, P., Imbard, M., and Lévy, C.: OPA 8.1 Ocean General Circulation Model reference manual., Note du Pôle de modélisation, Institut Pierre-Simon Laplace, 1998.

Marinov, I., Gnanadesikan, A., Toggweiler, J. R., and Sarmiento, J. L.: The southern ocean biogeochemical divide, Nature, 441 , 964-967, 2006.

Marsh, R., Nurser, A. J. G., Megann, A. P., and New, A. L.: Water mass transformation in the Southern Ocean of a global isopycnal coordinate GCM, J. Phys. Oceanogr., 30, 1013-1045, 2000.

Marshall, J., Jamous, D., and Nilsson, J.: Reconciling thermodynamic and dynamic methods of computation of water-mass transformation rates, Deep Sea Res. Pt. I, 46, 545-572, 1999.

McCartney, M. S.: Subantarctic Mode Water, in: A Voyage of Discovery?, edited by: Angel, M., 103-19, George Deacon 70th Anniversary Volume, 1977.

McDougall, T.: Thermobaricity, cabbeling, and water-mass conversion, J. Geophys. Res., 92, 5448-5464, 1987.

McNeil, B. and Tilbrook, B.: A seasonal carbon budget for the subAntarctic Ocean, South of Australia, Mar. Chem., 115, 196-210, 2009.

McNeil, B. I., Tilbrook, B., and Matear, R. J.: Accumulation and uptake of anthropogenic $\mathrm{CO}_{2}$ in the Southern Ocean, South of Australia between 1968 and 1996: The SAZ Project, J. Geophys. Res., 106, 31431-31445, 2001.

Mikaloff-Fletcher, S. E., Gruber, N., Jacobson, A. R., Gloor, M., Doney, S. C., Dutkiewicz, S., Gerber, M., Follows, M., Joos, F., Lindsay, K., Menemenlis, D., Mouchet, A., Muller, S. A., and Sarmiento, J. L.: Inverse estimates of the oceanic sources and sinks of natural $\mathrm{CO}_{2}$ and the implied oceanic carbon transport, Global Biogeochem. Cy., 21, GB1010, doi:10.1029/2006GB002751, 2007.

Naveira Garabato, A. C., Stevens, D. P., Watson, A. J., and Roether, W.: Short-circuiting of the oceanic overturning circulation in the Antarctic Circumpolar Current, Nature, 447, 194-197, 2007.

Nurser, A., Marsh, R., and Williams, R.: Diagnosing water mass formation from air-sea fluxes and surface mixing, J. Phys. Oceanogr., 29, 1468-1487, 1999.

Palter, J. B., Sarmiento, J. L., Gnanadesikan, A., Simeon, J., and Slater, R. D.: Fueling export production: nutrient return pathways from the deep ocean and their dependence on the Meridional Overturning Circulation, Biogeosciences, 7, 3549-3568, doi:10.5194/bg-7-3549-2010, 2010.

Radenac, M. H., Dandonneau, Y., and Blanke, B.: Displacements and transformations of nitrate-rich and nitrate-poor water masses in the tropical Pacific during the 1997 El Niño, Ocean Dyn., 55, 34-46, 2005.

Rodgers, K. B., Aumont, O., Madec, G., Menkes, C., Blanke, B., Monfray, P., Orr, J., and Schrag, D.: Radiocarbon as a thermocline proxy for the eastern equatorial Pacific, Geophys. Res. Lett., 31, 1-4, 2004.

Roullet, G. and Madec, G.: Salt conservation, free surface, and varying levels: a new formulation for ocean general circulation models, J. Geophys. Res., 105, 23927-23942, 2000.

Sabine, C. L., Feely, R. A., Gruber, N., Key, R. M., Lee, K., Bullister, J. L., Wanninkhof, R., Wong, C. S., Wallace, D. W. R., Tilbrook, B., Millero, F. J., Peng, T.-H., Kozyr, A., Ono, T., and Rios, A. F.: The oceanic sink for anthropogenic $\mathrm{CO}_{2}$, Science, 305, 367, 2004.

Sallée, J. B., Wienders, N., Speer, K., and Morrow, R.: Formation of 
subantarctic mode water in the southeastern Indian Ocean, Ocean Dyn., 56, 525-542, 2006.

Sarmiento, J. L., Gruber, N., Brzezinski, M. A., and Dunne, J. P.: High-latitude controls of thermocline nutrients and low latitude biological productivity, Nature, 427, 56-60, 2004.

Sloyan, B. M. and Rintoul, S. R.: The Southern Ocean limb of the global deep overturning circulation, J. Phys. Oceanogr., 31, 143173, 2001.

Talley, L. D., Reid, J. L., and Robbins, P. E.: Data-based meridional overturning streamfunctions for the global ocean, J. Climate, 16, 3213-3226, 2003.

Timmermann, R., Goosse, H., Madec, G., Fichefet, T., Ethe, C., and Dulière, V.: On the representation of high latitude processes in the ORCA-LIM global coupled sea ice-ocean model, Ocean modell., 8, 175-201, doi:10.1016/j.ocemod.2003.12.009, 2005.
Treguier, A. M., Held, I. M., and Larichev, V. D.: Parameterization of quasigeostrophic eddies in primitive equation ocean models, J. Phys. Oceanogr., 27, 567-580, 1997.

Valdivieso Da Costa, M. and Blanke, B.: Lagrangian methods for flow climatologies and trajectory error assessment, Ocean Modell., 6, 335-358, 2004.

Verdy, A., Dutkiewicz, S., Follows, M., Marshall, J., and Czaja, A.: Carbon dioxide and oxygen fluxes in the Southern Ocean: Mechanisms of interannual variability, Global Biogeochem. Cy., 21, GB2020, doi:10.1029/2006GB002916, 2007.

Walin, G.: On the relation between sea-surface heat flow and thermal circulation in the ocean, Tellus, 34, 187, 1982.

Zika, J. D., Sloyan, B. M., and McDougall, T. J.: Diagnosing the Southern Ocean Overturning from Tracer Fields, J. Phys. Oceanogr., 39, 2926-2940, 2009. 